Published in:

L. Bolzoni, T. Weissgaerber, B. Kieback, E.M. Ruiz-Navas and E. Gordo, Mechanical behaviour of pressed and sintered CP Ti and Ti-6Al-7Nb alloy obtained from master alloy addition powder, Journal of the Mechanical Behavior of Biomedical Materials, Apr. 2013, v. 20, p.149-161, http://dx.doi.org/10.1016/j.jmbbm.2012.08.022

(C) Elsevier 2013 


\title{
Mechanical Behaviour of Pressed and Sintered CP Ti and Ti-6Al-7Nb Alloy Obtained from Master Alloy Addition Powder
}

\author{
L. Bolzoni ${ }^{1}{ }^{1}$, T. Weissgaerber ${ }^{2}$, B. Kieback ${ }^{2}$, E.M. Ruiz-Navas ${ }^{1}$, E. Gordo ${ }^{1}$ \\ ${ }^{1}$ Departamento de Ciencia e Ingeniería de Materiales e Ingeniería Química \\ Universidad Carlos III de Madrid \\ Avda. de la Universidad, 30, 28911 Leganés (Madrid), Spain \\ ${ }^{2}$ Fraunhofer Institute of Manufacturing Technologies and Advanced Materials, \\ Powder Metallurgy and Composite Materials Dresden, \\ Winterbergstrasse 28, 01277 Dresden, Germany \\ *e-mail: bolzoni.leandro@gmail.com
}

\begin{abstract}
The Ti-6Al-7Nb alloy was obtained using the blending elemental approach with a master alloy and elemental titanium powders. Both the elemental titanium and the Ti-6Al-7Nb powders were characterised using X-ray diffraction, differential thermal analysis and dilatometry. The powders were processed using the conventional powder metallurgy route that includes uniaxial pressing and sintering. The trend of the relative density with the sintering temperature and the microstructural evolution of the materials sintered at different temperatures were analysed using scanning electron microscopy and X-ray diffraction. A minimum sintering temperature of $1200^{\circ} \mathrm{C}$ has to be used to ensure the homogenisation of the alloying elements and to obtain a pore structure composed of spherical pores. The sintered samples achieve relative density values that are typical for powder metallurgy titanium and no intermetallic phases were detected. Mechanical properties comparable to those specified for wrought Ti-6Al-7Nb medical devices are normally obtained. Therefore, the produced materials are promising candidates for load bearing applications as implant materials.
\end{abstract}

Keywords: Ti-6Al-7Nb, titanium powder metallurgy, blending elemental (BE), master alloy, flexural properties

\section{Introduction}

Among the various high-performance engineering materials that are employed as biomaterials, such as polymeric biomaterials, ceramics and glasses, metallic biomaterials continue to be used due to their high strength, resistance to fracture and their relative ease of fabrication. Austenitic stainless steel, Co-based alloys (Co-Cr-Mo) and precious metals are 
normally used for these applications. Titanium and its alloys present an attractive combination of properties, especially due to their superior biocompatibility and corrosion resistance in conjunction with low density and an elastic modulus that is more similar to that of the human bones (Niinomi, 1998). Titanium was first considered for biomedical applications in the 1950s (Lütjering and Williams, 2003; Donachie, 1988), especially the Ti-6Al-4V alloy. Subsequently, two different generations of new compositions of titanium alloys with tailored properties have been developed. The first one corresponds to alloys with properties that are similar to those of Ti-6Al-4V but that are V-free due to the supposed cytotoxicity of vanadium with the body tissues. Examples of materials in this group include the Ti-6Al-7Nb and Ti-5Al-2.5Fe alloys. The second one corresponds to alloys that have an enhanced biocompatibility and lower elastic modulus, and these alloys specifically include the use of niobium and zirconium, such as the Ti-13Nb-13Zr alloy. For example, the Ti-6Al-7Nb alloy has primarily been used for producing cementless anchored hip prosthesis stems and elastic deformable cup shells (Semlitsch et al., 1985). The microstructure and the properties, especially the mechanical behaviour, of this alloy have been well studied for specimens obtained by ingot metallurgy or by casting. Nevertheless, extensive research has not been performed on the powder metallurgy route, which enables the properties of the alloy to be tailored by modifying the sintering parameters. Furthermore, the works available in the literature consider advanced powder metallurgy methods such as hot-pressing (Henriques et al., 2001) and metal injection moulding (Itoh et al., 2007; Shi-bo et al., 2005). Therefore, there is a lack of studies concerning the processing of this alloy using conventional powder metallurgy techniques. The present work focuses on the production of the Ti-6Al-7Nb titanium alloy through the blending elemental approach by master alloy addition combined with its processing using the conventional powder metallurgy route, namely pressing and sintering (P\&S). Simultaneously, the elemental titanium powder used for fabricating the Ti$6 \mathrm{Al}-7 \mathrm{Nb}$ alloy was processed for use as a reference. The primary objective of this work was the synthesis of the two previously mentioned materials by pressing and sintering to identify the most suitable processing conditions. These conditions should guarantee a homogeneous distribution of the alloying elements and achieve an appropriate microstructure to provide appropriate mechanical properties for implant applications. An in-depth analysis of the variation in the mechanical properties studied as a function of the most relevant aspects that affect them, specifically the relative density, the microstructural features and the content of interstitial elements, was considered. 


\section{Experimental Procedure}

For this study, three starting powders were purchased: a hydride-dehydride (HDH) elemental titanium powder and a niobium:aluminium:titanium master alloy from GfE Gesellschaft für Elektrometallurgie $\mathrm{mbH}$ and an elemental aluminium from Sulzer Metco Ltd. The characteristics of the starting powders (provided by the suppliers) are reported in Table 1. The detailed preparation of the Ti-6Al-7Nb alloy powder can be found elsewhere (Bolzoni et al., 2012a). Briefly, the master alloy was milled to reduce the particle size and to adjust the composition, and it was then blended with elemental titanium in a "turbula" mixer for 30 minutes. X-ray diffraction (XRD) patterns $\left(2 \theta=20-120^{\circ}\right)$ of both elemental titanium and Ti6Al-7Nb powders were obtained using a Bruker AXS D8-Advance diffractometer equipped with a $\mathrm{Cu} \mathrm{K} \alpha_{1}$ radiation source. Furthermore, a differential thermal analysis (DTA) using a Netzsch STA 449 C Júpiter DTA analyser was performed by heating the loose powder to $1400^{\circ} \mathrm{C}$ (heating rate $10^{\circ} \mathrm{C} / \mathrm{min}$ ) under an inert atmosphere (Ar). The powder was maintained at the maximum temperature for 15 minutes and finally cooled to room temperature at a rate of $10^{\circ} \mathrm{C} / \mathrm{min}$. Green specimens were cold uniaxially pressed at $700 \mathrm{MPa}$ using a floating die and zinc stearate as lubricant for the walls of the die. A dilatometric study of the green samples using a NETZSCH DIL 402 E dilatometer was performed using the same parameters for the DTA analysis. The dilatometric study was performed using a constant flow of argon at a rate of $90 \mathrm{ml} / \mathrm{min}$ to prevent oxidation of the specimens. The specimens were sintered under high vacuum (approximately $10^{-5}$ mbar) at a temperature ranging between $900^{\circ} \mathrm{C}$ and $1400^{\circ} \mathrm{C}$ and then cooled at a rate of $5^{\circ} \mathrm{C} / \mathrm{min}$ after a dwell time of 2 hours. Microstructural analysis was performed using a SEM operating in backscattering mode, and the distribution of the alloying elements was examined using energy-dispersive X-ray spectroscopy (EDS). The metallographic preparation was done using the conventional technique, and the microstructure was chemically etched using Kroll's reagent to reveal the phases that compose the microstructure. The mechanical characterisation was performed using hardness measurement and the three-point bending tests (ASTM B528) to measure the strength and the strain of the sintered materials. Finally, the content of oxygen and nitrogen, which are two interstitial elements that have the greatest effect on the mechanical properties of titanium, were measured using the inert gas fusion technique. For this measurements, a LECO TC500 calibrated with appropriated standard samples was employed.

\section{Results and Discussion}




\subsection{XRD analysis of the powders}

The XRD patterns of the elemental titanium and the Ti-6Al-7Nb powders are shown in Figure 1.

As seen in Figure 1 a), the only phase that was observed in the elemental powder is the alpha phase. This finding was expected because this material does not contain any alloying elements that would stabilise the beta phase at room temperature, and the contaminants, oxygen, nitrogen and carbon, are alpha stabilisers. In the XRD pattern of the Ti-6Al-7Nb powder (Figure $1 \mathrm{~b}$ ), it was possible to identify the elements employed during its production, including elemental titanium (alpha), elemental aluminium and an Al:Nb master alloy, which is identified as the $\mathrm{AlNb}_{2}$ phase.

\subsection{Differential Thermal Analysis (DTA)}

The results of the DTA analyses performed on the loose elemental titanium and Ti-6Al-7Nb powders are presented in Figure 2.

From the analyses of the DTA heating curves shown in Figure 2, it can be seen that the only remarkable event for elemental titanium is the endothermic peak at approximately $900^{\circ} \mathrm{C}$, which coincides with the allotropic transformation of titanium. The onset temperature of the alpha to beta phase transformation is $875^{\circ} \mathrm{C}$, which is very near the nominal beta transus of elemental titanium, as shown in Table 2.

In the case of the Ti-6Al-7 $\mathrm{Nb}$ powder prepared by master alloy addition, three characteristic features were detected during the DTA analysis, as shown in Figure 2 and Table 2. Specifically, the first endothermic peak at approximately $330^{\circ} \mathrm{C}$ corresponds to the elimination of the wax used as process control agent during milling of the $\mathrm{Nb}$ :Al:Ti master alloy, whereas the second endothermic peak at $900^{\circ} \mathrm{C}$ corresponds to the alpha to beta transformation. This temperature is lower than the nominal beta transus of the titanium alloys considered (see Table 2), and it is due to the powder production method. This result arises because the alloying elements are added as master alloy and have to diffuse inside of the titanium matrix. The exothermic peak observed at approximately $660^{\circ} \mathrm{C}$ is due to some type of interaction between elemental titanium and the elemental aluminium powder that was added to achieve the desired composition. Based on the Ti-Al phase diagram (Murray, 1987) and assuming that an elemental titanium particle is locally in contact with an elemental aluminium particle that melts and diffuses, different titanium aluminates, such as $\mathrm{Ti}_{3} \mathrm{Al}, \mathrm{TiAl}$ and $\mathrm{TiAl}_{3}$, could be formed at $660^{\circ} \mathrm{C}$. Studies concerning the diffusion in the titanium-aluminium system (van Loo and Rieck, 1973a; van Loo and Rieck, 1973b) and the exothermic nature of the 
reaction that occurs indicate the formation of the intermetallic compound $\mathrm{TiAl}_{3}(\mathrm{Böhm}$ and Kieback, 1998).

\subsection{Dilatometric study}

The dilatometric curves and the details obtained from their analyses are presented in Figure 3 and Table 3, respectively.

From Figure 3, there is no significant dimensional variation of elemental titanium up to $870^{\circ} \mathrm{C}$, point from which the shrinkage of the samples is observed. The start of the shrinkage process coincides with the allotropic phase transformation for the H.C.P. $(\alpha)$ to the B.C.C. ( $\beta$ ) phase (Table 3). Concerning the Ti-6Al-7Nb alloy, the obtained dilatometric curve contains some significant differences with respect to that of elemental titanium. The first remarkable difference is the swelling of the samples, approximately $0.7 \%$, which begins at $500^{\circ} \mathrm{C}$ and culminates at $620^{\circ} \mathrm{C}$ from where the $\mathrm{dL} / \mathrm{L}_{0}$ parameter starts to decrease. This effect is due to the diffusion of the elemental aluminium added during the preparation of the titanium alloys, which reacts with elemental titanium and forms the intermetallic compound $\mathrm{TiAl}_{3}$, as revealed from the DTA analysis (Figure 2). This exothermic reaction induces a small swelling of the samples, as shown in Figure 3. It has been reported that this reaction could induce a delay in the shrinkage and consequently, in the beginning of the sintering of the samples (Böhm and Kieback, 1998; Ivasishin, 2005). Nevertheless, form the data reported in Table 3, it can be seen that the Ti-6Al-7Nb powder blend has an onset temperature of $812^{\circ} \mathrm{C}$. This temperature is lower than that of elemental titanium, which is most likely due to the diffusion of the alloying elements, especially elemental aluminium. Another important difference compared to elemental titanium is the maximum shrinkage experienced by the specimens, which is greater for the Ti-6Al-7 $\mathrm{Nb}$ alloy. This contraction occurs even though the same compaction pressure was employed and similar green density was obtained (86\%), and it is most likely a result of the diffusion of the alloying elements through the titanium lattice. Finally, it can also be observed that the mean contraction rate of the Ti-6Al-7Nb alloy during heating in the temperature range of $950-1400^{\circ} \mathrm{C}$ is greater $\left(1.17 \times 10^{-4}{ }^{\circ} \mathrm{C}^{-1}\right)$ than that of elemental titanium $\left(0.86 \times 10^{-4}{ }^{o} \mathrm{C}^{-1}\right)$.

\subsection{Microstructural evolution during sintering of HDH elemental titanium}

The microstructural evolution of the $\mathrm{HDH}$ elemental titanium powder during vacuum sintering in the range of $900-1400^{\circ} \mathrm{C}$ can be seen in Figure 4.

As shown in Figure 4, the only microconstituent of the sintered specimens composed of elemental titanium is the alpha phase, and consequently, the difference between one sintering 
temperature and the other is the residual porosity and mean grain size. In particular, it can be observed that the mean grain size increases with the processing temperature, and it changes from a distribution of equiaxed grains at $900^{\circ} \mathrm{C}$ (Figure 4 a) to elongated and more irregular grains at $1400^{\circ} \mathrm{C}$ (Figure $4 \mathrm{f}$ ). Furthermore, it can also be observed that the percentage of residual porosity decreases with increasing sintering temperature and the pores become more spherical. Specifically, at $900^{\circ} \mathrm{C}$, the porosity is irregular and concentrated on the boundaries between the former powder particles, which is in agreement with the dilatometric study that revealed that the shrinkage of the samples (sintering) simultaneously begins with the alpha to beta transformation. Increasing the sintering temperature to $1000^{\circ} \mathrm{C}$ (Figure $4 \mathrm{~b}$ ) induces the interdiffusion of titanium because the interparticle boundaries disappear, but the porosity is still irregular although some small round pores are visible. At $1100^{\circ} \mathrm{C}$ (Figure $4 \mathrm{c}$ ), the porosity is primarily spherical, but there are still some irregular pores. Nevertheless, the total amount of residual porosity appears to be significantly lower. With a further increase of the sintering temperature (Figure $4 \mathrm{~d}$, e and $\mathrm{f}$ ), the rounding of the pores and the decrease of the residual porosity continue and the material undergoes pronounced grain growth.

\subsection{Microstructural evolution during sintering of the Ti-6Al-7Nb alloy}

The microstructural evolution of the Ti-6Al- $7 \mathrm{Nb}$ alloy sintered at different temperatures $(900-$ $1400^{\circ} \mathrm{C}$ ) is shown in Figure 5.

The processing of the master alloy addition Ti-6Al-7Nb powder at a sintering of $900^{\circ} \mathrm{C}$ results in a microstructure that is composed of powder particles where the interparticle boundaries are still clearly identifiable and the diffusion of the alloying elements has just begun (Figure 5 a). Furthermore, it can be observed that near the Al:Nb:Ti master alloy particles, where niobium has already started to diffuse and whose concentration is locally greater, small two-phase islands of the lamellar structure become distinguishable. The compositional change in the areas close to an $\mathrm{Al}: \mathrm{Nb}$ master alloy particle every $10 \mu \mathrm{m}$ was analysed by EDS, and the results are shown in Figure 6.

From Figure 6, it can be seen that, at the border of the Al:Nb particle, the contents of aluminium and niobium are quite high, which are 26 at.\% and 12 at.\%, respectively. The percentages of these two elements decrease to approximately 11 at.\% and 4 at. $\%$ at $10 \mu \mathrm{m}$. Similar values are obtained at $20 \mu \mathrm{m}$ from the master alloy particle, but then there is a further decrease in the percentage of the alloying elements at $30 \mu \mathrm{m}$ from the master alloy particle. The observed behaviour is equivalent to the increase in the titanium content from 63 at.\% (near the master alloy particle) to 96 at.\% at $30 \mu \mathrm{m}$ from the master alloy particle. This result 
confirms that the alloying elements are diffusing and that the local content of niobium is sufficiently high to stabilise the beta phase, because the maximum solubility of niobium in $\alpha$ Ti is $2.2 \pm 0.5$ at.\% (Murray, 1987).

The microstructure of the samples sintered at $1000^{\circ} \mathrm{C}$ (Figure $5 \mathrm{~b}$ ) resembles that of those processed at $900^{\circ} \mathrm{C}$ because the features are the same and the pores are still primarily irregular, although they are considerably less interconnected. This result is primarily due to an important interdiffusion between the elemental titanium particles and diffusion of the alloying elements towards the titanium matrix. The master alloy particles are still visible, but the particle size is smaller and the morphology becomes spherical. Furthermore, the two-phase islands are considerable more distributed throughout the microstructure. EDS analyses performed near the master alloy particle provides similar results to those shown in Figure 6, but the amount of alloying elements is greater, between $20 \%$ (position 1) and $80 \%$ (position 4), with respect to the values observed in the samples sintered at $900^{\circ} \mathrm{C}$. This result is due to the faster diffusion of aluminium compared to niobium and titanium, which results in Kirkendall pores inside the master alloy particle, which are clearly visible in Figure 7, a magnification of Figure $5 \mathrm{~b}$ ).

At the sintering temperature of $1100^{\circ} \mathrm{C}$ (Figure $5 \mathrm{c}$ ), the alloying elements appear practically dissolved, although chemical homogeneity is not completed (Table 4), and the microstructure developed, showing $\alpha$ grains surrounded by $\alpha+\beta$ lamellae but there is still an important amount of residual porosity. As for the elemental titanium powder, a further increase of the sintering temperature leads to the spheroidisation of the pores and to a decrease in the total amount of pores. Increasing the sintering temperature also induces growth of the mean grain size of the alpha phase, and consequently, increases the length of the intergranular $\alpha+\beta$ lamellae. EDS chemical analyses were performed on the specimens sintered from $1100^{\circ} \mathrm{C}$ to $1400^{\circ} \mathrm{C}$, and the results are presented in Table 4 . The data presented in table 4 appear to corroborate the results of the microstructural evolution of Figure 5; therefore, the homogenisation of the alloying elements is completed at $1200^{\circ} \mathrm{C}$. Consequently, this sintering temperature should be used to ensure the complete diffusion of the alloying elements when adding a master alloy to elemental titanium to produce the Ti-6Al-7Nb alloy.

The results of the chemical analyses performed on the alpha grains and on the beta lamellae are presented in Table 5.

As shown in Table 5, the alpha phase contains approximately 2 at.\% of niobium, which is in agreement with the Ti-Nb binary phase diagram, where the maximum solubility of niobium in $\alpha$-Ti is $2.2 \pm 0.5$ at.\% (Murray, 1987). On average, the chemical composition of the alpha and 
beta phases can be summarised in atomic percentage as $88.1 \mathrm{Ti}-10.0 \mathrm{Al}-1.9 \mathrm{Nb}$ and $81.7 \mathrm{Ti}$ 5.0Al-13.3 $\mathrm{Nb}$, respectively.

\subsection{XRD analysis of the sintered materials}

Figure 8 shows the XRD patterns for the specimens sintered at $900^{\circ} \mathrm{C}, 1100^{\circ} \mathrm{C}$ and $1400^{\circ} \mathrm{C}$ for the HDH elemental titanium powder and the master alloy addition Ti-6Al-7Nb titanium alloy. As expected, the only phase detected in the specimens composed of the HDH elemental titanium is the alpha phase, irrespective of the employed sintering temperature (Figure $8 \mathrm{a}$ ). However, for the specimens produced using the master alloy addition Ti-6Al-7Nb powder that was sintered at $900^{\circ} \mathrm{C}$ (Figure $8 \mathrm{~b}$ ), two-phases were detected, alpha-titanium and the $\mathrm{AlNb}_{2}$ phase. This latter phase was previously observed in the starting powder (Figure 1), and it is still present at $900^{\circ} \mathrm{C}$ because, as shown in Figure 5 a), at $900^{\circ} \mathrm{C}$ the diffusion of the alloying elements from the master alloy particles toward titanium is quite limited.

Nevertheless, the relative intensity of the diffraction peaks that correspond to the $\mathrm{AlNb}_{2}$ phase is lower than that in the starting powder, which confirms that some diffusion has already occurred, as explained on the basis of the microstructural evolution (Figure $5 \mathrm{a}$ ). When increasing the sintering temperature, the dissolution of the master alloy particles continues, and at $1100^{\circ} \mathrm{C}$, no $\mathrm{AlNb}_{2}$ phase was detected, which is in agreement with the microstructural evolution results (Figure $5 \mathrm{c}$ ). Furthermore, at this processing temperature, the alloying elements and, especially, niobium is sufficiently dissolved in the titanium matrix to stabilise the beta phase, which was observed in the XRD pattern. A further increase of the sintering temperature does not change the phases that appear in the XRD pattern, as shown in Figure 8 b). Note that even if elemental titanium and elemental aluminium react at approximately $655^{\circ} \mathrm{C}$ to form the intermetallic compound $\mathrm{TiAl}_{3}$, as shown in Figure 2 and Table 2, this intermetallic phase was not observed during the XRD analyses of the sintered specimens, even at the lowest processing temperature studied. This result could either be because the intermetallic dissolves during the sintering of the powder or its volume fraction is lower than the detection limit of X-ray diffraction.

\subsection{Relative density of the sintered materials}

The variation in the relative density of the sintered specimens, which was calculated using the Archimedes method, is presented in Figure 9. It is worth mentioning that the relative density of elemental titanium was calculated using as theoretical density of the material the value of the density of the powder measured by helium picnometry $\left(4.51 \mathrm{~g} / \mathrm{cm}^{3}\right)$ because the powder 
does not present any internal porosity. In the case of the Ti-6Al-7 Nb alloy, the employment of the value of the density of the powder obtained by helium picnometry was not possible because the value determined by helium picnometry was affected, specifically lowered, by the wax used during milling of the master alloy; therefore, the nominal value of $4.52 \mathrm{~g} / \mathrm{cm}^{3}$ (Boyer et al., 1998) was employed.

As shown in Figure 9, as expected, the relative density of both elemental titanium and the Ti$6 \mathrm{Al}-7 \mathrm{Nb}$ alloy increases with increasing sintering temperature, but there are some features that cause the curves to deviate from the hypothetical asymptotic behaviour. The first feature that can be observed is the slight difference in the relative density between elemental titanium and the alloy in the range of $900-1100^{\circ} \mathrm{C}$, which was expected from the comparison of the total amount of residual porosity visible in their respective microstructures (Figure 4 and Figure 5). The second feature is the relative density of both specimens sintered at $1200^{\circ} \mathrm{C}$,

which is less than the expected based on the trend shown in Figure 9. Because no reactions or transformation were detected in either the DTA analyses (Figure 2) or in the dilatometric study (Figure 3) and no new or unexpected phases were identified in the XRD patterns (Figure 6 and 7) or during the microstructural analysis (Figure 4 and Figure 5), further study is required. The highest values obtained, which were approximately $96 \%$ for both materials, are similar to the values observed in other works (Abkowitz and Rowell, 1986; Froes et al., 2002; Bolzoni et al., 2011).

\subsection{Mechanical characterisation}

As stated in the experimental procedure, the sintered samples were mechanically characterised using three-point bending tests (ASTM B528). Representative examples of the load-deflection curves for both elemental titanium and the blended elemental Ti-6Al-7Nb alloy specimens are shown in Figure 10. Specifically, the curves refer to the samples sintered at $900^{\circ} \mathrm{C}, 1100^{\circ} \mathrm{C}$ and $1300^{\circ} \mathrm{C}$.

As shown in Figure 10, with the obtained relative density values (Figure 9), elemental titanium and the Ti-6Al-7 Nb alloy present a very similar elastic behaviour, and they consequently have similar flexural moduli. Nevertheless, during the three-point bending tests, the Ti-6Al-7Nb alloy samples behave as a brittle material and fail without any appreciable plastic deformation, whereas the elemental titanium specimens exhibit a pronounced plastic deformation before fracture. Concerning the fracture surface of the samples, it can be observed that the specimens sintered at $900^{\circ} \mathrm{C}$ fail through intergranular fracture because the fracture primarily occurs by grain-boundary separation (intercrystalline fracture). This result 
is clearly visible through the grain boundaries "in relief" for elemental titanium, whereas for the Ti-6Al-7Nb alloy, this effect is mitigated by the presence of master alloy particles, which act as a weak grain boundary phase. However, the samples sintered at $1300^{\circ} \mathrm{C}$ exhibit the typical cleavage fracture of metals with a H.C.P. lattice and many river markings can be clearly distinguished within the grains (transcrystalline fracture). The fracturing of the samples sintered at $1100^{\circ} \mathrm{C}$ is somewhere in between the two previously described behaviours because intergranular fracture can be observed but there are also visible river markings within some grains. This switching of the fracture mode from intercrystalline to transcrystalline is in agreement with the results shown and is primarily a consequence of the microstructural evolution (Figure 4 and Figure 5) because at $900^{\circ} \mathrm{C}$, the pore structure is primarily interconnected and composed of irregular pores, whereas at $1300^{\circ} \mathrm{C}$, the spherical pores are completely isolated.

The formula reported in the ASTM B528 standard for calculating the transverse rupture strength is applicable to relatively brittle materials but, as just shown, the elemental titanium samples are characterised by an evident plastic deformation. Therefore, the values of the $\sigma_{0.2}$ are considered, and they are presented for each material as a function of the sintering temperature in Figure 11.

As shown in Figure 11, the yield strength of the sintered samples has two different trends for the two materials because it always increases for elemental titanium, whereas it increases up to the $1200^{\circ} \mathrm{C}$ sintering temperature and then decreases for the Ti-6Al-7Nb alloy.

Furthermore, it can also be observed that the yield strength of the Ti-6Al-7Nb alloy sintered in the range of $1100-1300^{\circ} \mathrm{C}$ is greater than that of elemental titanium. This behaviour is, once again, a direct consequence of the microstructural evolution, and the Ti-6Al-7Nb alloy becomes stronger when the diffusion of the alloying elements throughout the titanium matrix is almost terminated. The $\sigma_{0.2}$ values shown in Figure 11 are generally similar to the values observed when testing specimens composed of the materials studied in this work (Bolzoni et al., 2012b), and the Ti-6Al-4V alloys (Bolzoni et al., 2012c) processed using conventional hot-pressing and somewhat higher with respect to the value specified for the flexural strength of wrought Ti-6Al-7Nb medical devices (935-995 MPa) (Henry, 2009). The only exceptions are the samples sintered at low temperature $\left(900^{\circ} \mathrm{C}\right.$ and $\left.1000^{\circ} \mathrm{C}\right)$, especially for the Ti-6Al$7 \mathrm{Nb}$ alloy, due to the residual porosity and the non-homogeneous microstructure.

The values of the maximum bending strength and flexural strain obtained using the threepoint bending test are reported in Table 6 . 
Regarding the maximum bending strength data shown in Table 6, it can be observed that the strength of elemental titanium increases with the sintering temperature, but once the temperature exceeds $1200^{\circ} \mathrm{C}$, the strength remains almost constant. This result indicates that from this processing temperature, the positive effect of reducing the residual porosity is counterbalanced by the grain growth induced by increasing the sintering temperature. From the maximum bending strength values of the Ti-6Al-7Nb alloy, which coincide with the yield strength values, it appears that the coarser microstructure obtained in the specimens sintered at $1400^{\circ} \mathrm{C}$ results in a significant reduction of the bending strength. As already assumed based on the trend of the yield strength (Figure 11), the Ti-6Al-7Nb alloy achieves higher bending strength compared to elemental titanium only when it is sintered in the range of $1100-1300^{\circ} \mathrm{C}$. Concerning the flexural strain values, it can be observed that this property has the same tendency of the strength of the Ti-6Al-7Nb alloy because it increases up to a certain sintering temperature and then starts to decrease. Furthermore, the elemental titanium samples always achieve greater flexural strain, which is in agreement with the load-deflection curve where it was shown that elemental titanium undergoes a pronounced plastic deformation before fracture.

To better understand the mechanical behaviour just described for elemental titanium and the Ti-6Al-7Nb alloy obtained by pressing and sintering, the contents of oxygen and nitrogen were measured and they are presented in Table 7.

From the analyses of the oxygen and nitrogen data shown in Table 7, it can be seen that the content of both elements generally increases with increasing the sintering temperature. The trends just described fit better for the Ti-6Al-7Nb alloy, whereas in the case of elemental titanium, there are some exceptions, such as the specimens sintered at $1100^{\circ} \mathrm{C}$ and $1300^{\circ} \mathrm{C}$. This behaviour occurs because the sintering step is discontinuously conducted in batches. This process results in different levels of vacuum, which corresponds to a different level of contamination from the processing atmosphere. Nevertheless, the final oxygen and nitrogen content of the material is also significantly influenced by the manipulation of the powder and of the green samples and the amount of oxygen and nitrogen adsorbed into the titanium powder particles. Concerning the absolute values of the content of oxygen and nitrogen, it can also be seen in Table 7 that the oxygen content is approximately $0.4 \mathrm{wt} . \%$, whereas the nitrogen content is slightly less than $0.03 \mathrm{wt} \%$. The amount of oxygen dissolved into the pressing and sintering elemental titanium is less than the maximum amount of oxygen specified for CP Ti grade 4, and it is accordingly comparable in terms of mechanical properties. In the case of the pressed and sintered $\mathrm{Ti}-6 \mathrm{Al}-7 \mathrm{Nb}$ alloy, the final content of 
oxygen dissolved in the material is, at least, twice the amount indicated for the ASTM F1295 alloy (Boyer et al., 1998). Therefore, this factor should be considered during the comparison of the mechanical properties. Regarding the nitrogen content, it has been previously said that the content is approximately $0.03 \mathrm{wt} . \%$ for both elemental titanium and the Ti-6Al-7Nb alloy. This percentage is exactly the maximum amount of nitrogen allowed for many titanium alloys.

It is well known that interstitial elements, such as oxygen, nitrogen and carbon, strengthen and harden titanium and titanium alloys (Jaffee and Campbell, 1949; Jaffee et al., 1950; Finlay and Snyder, 1950). In the case of elemental titanium obtained by the pressing and sintering route, the increasing contents of oxygen and nitrogen induces a continuous increase of both the yield and maximum bending strengths of the material. In a global view, it can be stated that the increase of the relative density (equivalent to a reduction of the residual porosity and consequently to a lesser amount of stress intensity factor sites) and the increase in the amount of interstitials overcome the effect of the grain growth induced by a higher sintering temperature. Consequently, the strength of the pressed and sintered elemental titanium samples continuously increases. However, the positive effect of reducing the residual porosity and of the homogenisation of the microstructure induces a constant increase in the flexural strain of elemental titanium, with the exception of the specimens sintered at $1400^{\circ} \mathrm{C}$, where the fragilising effect of the high oxygen content results in an important loss of ductility. Considering the Ti-6Al-7Nb alloy, the increase of the relative density combined with the increase in the contents of both oxygen and nitrogen induces an increase in the strength of this alloy fabricated by pressing and sintering. Nevertheless, starting from a processing temperature of $1300^{\circ} \mathrm{C}$, the presence of the alloying elements but, primarily, the grain growth, leads to a reduction of both the yield and the maximum bending strength. As in the case of elemental titanium, the ductility of the Ti-6Al-7Nb alloy is favoured by the reduction of the residual porosity and of the grain growth and consequently increases with the sintering temperature. Nevertheless, starting from a processing temperature of $1300^{\circ} \mathrm{C}$, the effect of the interstitials is very powerful, and the flexural strain starts to decrease.

As already stated, although residual porosity is present (in between 3\% and 10\%), the bending strength of the materials studied in this work is greater than the normal range of flexural strength indicated for wrought Ti-6Al-7Nb medical devices. This result is primarily due to the greater amount of oxygen dissolved in the materials, although a contribution from the finer microstructure of powder metallurgy materials cannot be disregarded. 
Finally, the results of the hardness measurements conducted on cross-sections of the sintered specimens are plotted versus the sintering temperature in Figure 12.

As shown in Figure 12, the hardness of both elemental titanium and Ti-6Al-7Nb samples continuously increases with the sintering temperature. This behaviour is typical of powder metallurgy materials because a higher processing temperature corresponds to a higher relative density (Figure 9) and consequently a lesser amount of residual porosity. Nevertheless, in this case, this behaviour also greatly depends on the microstructural evolution, which is made clear by comparing the hardness of the two materials. At low sintering temperatures, such as $900^{\circ} \mathrm{C}$ and $1000^{\circ} \mathrm{C}$ where the two materials have equal relative density values, the hardness difference is approximately $30 \mathrm{HV}$ due to the inhomogeneous microstructure of the blended elemental Ti-6Al-7 Nb alloy. This difference increases with the sintering temperature and reaches a difference of approximately $100 \mathrm{HV}$ at $1300^{\circ} \mathrm{C}$ and $1400^{\circ} \mathrm{C}$, which is primarily due to the presence of the alloying elements that diffused into the titanium matrix and resulted in the formation of the typical microstructure of the $\alpha+\beta$ titanium alloys composed of $\alpha$ grains and $\alpha+\beta$ lamellae (Figure 5). In comparison to the hardness value of the wrought materials, elemental titanium samples reach the hardness of CP grade 4 (253 HV) (Boyer et al., 1998) exclusively at $1400^{\circ} \mathrm{C}$ whereas the Ti-6Al-7Nb specimens reach comparable value to the IMI 367 alloy (270-290 HV) (Henry, 2009) at approximately $1250^{\circ} \mathrm{C}$. Again, the higher hardness of the pressed and sintered elemental titanium and Ti-6Al-7Nb alloy compared to the respective wrought materials is due to the effect of the interstitials because oxygen and nitrogen considerably harden titanium (Jaffee and Campbell, 1949; Jaffee et al., 1950; Finlay and Snyder, 1950).

\section{Conclusions}

From this study on the production of the Ti-6Al-7Nb alloy by the conventional powder metallurgy route (uniaxial pressing and sintering) in combination with the master alloy addition approach, the following can be concluded:

- Elemental titanium reacts with elemental aluminium to form the intermetallic compound $\mathrm{TiAl}_{3}$, but this does not appear to be detrimental for the material because the intermetallic appears to either dissolve or its volume fraction is lower than the detection limit of the XRD technique;

- The shrinkage of the sample begins in conjunction with the allotropic transformation, and the maximum length reduction of the Ti-6Al-7Nb alloy is greater, which is most likely due to the presence of the alloying elements; 
- Below a specific sintering temperature, $1100^{\circ} \mathrm{C}$, the residual porosity is irregular and still primarily interconnected, and a further increase in the sintering temperature results in the spheroidisation of the pores and grain growth;

- The microstructure of the Ti-6Al-7Nb alloy produced using the powder metallurgy route is composed of alpha grains and $\alpha+\beta$ lamellae; the typical laminar microstructure of the $\alpha+\beta$ titanium alloys slow cooled from a temperature greater than the $\beta$ transus. Nevertheless, from this study, it can be stated that a minimum sintering temperature of $1200^{\circ} \mathrm{C}$ should be selected to ensure a homogeneous distribution of the alloying elements.

- The relative density of both elemental titanium and the titanium alloy increases with the sintering temperature and reaches values of $96-97 \%$;

- The three-point bending tests reveal that elemental titanium deforms plastically, whereas the Ti-6Al-7Nb alloy behaves as a brittle material and there is a change in the fracture mode, from intercrystalline to transcrystalline, with the increase of the sintering temperature. Generally, mechanical properties, such as the yield or maximum bending strength and hardness, comparable to those of the respective wrought materials are obtained.

\section{Acknowledgements}

The authors want to acknowledge the financial support from the Spanish Ministry of Science through the R\&D Projects MAT2009-14448-C02-02 and MAT2009-14547-C02-02, and from Regional Government of Madrid through the ESTRUMAT (S2009/MAT-1585) project.

\section{References}

Abkowitz S., Rowell, D., 1986. Superior Fatigue Properties for Blended Elemental P/M Ti6Al-4V. Journal of Metals, pp. 36-39.

Bolzoni, L., Esteban, P. G., Ruiz-Navas, E. M., Gordo, E., 2011. Influence of Powder Characteristics on Sintering Behaviour and Properties of PM Ti Alloys Produced from Prealloyed Powder and Master Alloy. Powder Metallurgy 54, 543-550.

Bolzoni, L., Ruiz-Navas, E. M, Neubauer, E., Gordo, E., 2012. Inductive Hot-pressing of Titanium and Titanium Alloy Powders. Materials Chemistry and Physics 131, 672-679.

Bolzoni, L., Ruiz-Navas, E. M, Neubauer, E., Gordo, E., 2012. Mechanical Properties and Microstructural Evolution of Vacuum Hot-pressed Titanium and Ti-6Al-7Nb Alloy. Journal of the Mechanical Behavior of Biomedical Materials 9C, 91-99. 
Bolzoni, L., Ruiz-Navas, E. M, Montealegre Meléndez, I., Gordo, E., 2012. Microstructural Evolution and Mechanical Properties of the Ti-6Al-4V Alloy Produced by Vacuum Hotpressing. Materials Science and Engineering A 546, 189-197.

Boyer, R., Welsch, G., Collings, E. W., 1998. Materials Properties Handbook: Titanium Alloys, Second ed. ASM-International, Ed. Ohio, USA.

Böhm and Kieback, 1998. Investigation of Swelling Behaviour of Ti-Al Elemental Powder Mixtures during Reaction Sintering. Zeitschrift für Metallkunde 89, 90-95

Donachie, M. J., 1988. Titanium. A Technical Guide. ASM International, 1-223.

Finlay W. L. and Snyder, J. A., 1950. Effects of Three Interstitial Solutes (Nitrogen, Oxygen and Carbon) on the Mechanical Properties of High-purity Alpha Titanium. Journal of Metals 188, 277-286.

Froes, F. H., Ivasishin, O.M., Moxson, V. S., Savvakin, D. G., Bondareva, K.A., Demidik, A. M., 2002. Cost-effective Synthesis of Ti-6A1-4V Alloy Components via the Blended Elemental P/M Approach, in: Symposium on TMS Symposium on High Performance Metallic Materials for Cost Sensitive Applications, Seattle, WA.

Henriques, V. A. R., Bellinati, C. E., da Silva, C. R. M., 2001. Production of Titanium Alloys for Medical Implants by Powder Metallurgy. Key Engineering Materials vol. Advanced Powder Technology II, 443-448.

Henry D., 2009. Materials and Coatings for Medical Devices: Cardiovascular. Ohio, USA, ASM International, 151-186.

Itoh, Y., Miura, H., Sato, K., Niinomi, M., 2007. Fabrication of Ti-6Al-7Nb Alloys by Metal Injection Molding. Materials Science Forum, Progress in Powder Metallurgy, Pts 1 and 2, 357-360.

Ivasishin, O. M., 2005. Cost-effective Manufacturing of Titanium Parts with Powder Metallurgy Approach. Materials Forum 29, 1-8.

Jaffee, R. I. and Campbell, I. E., 1949. The Effect of Oxygen, Nitrogen and Hydrogen on Iodide Refined Titanium. Transactions of the American Institute of Mining and Metallurgical Engineers 185, 646-654.

Jaffee, R. I., Ogden, H. R., Maykuth, D. J., 1950. Alloys of Titanium with Carbon, Oxygen and Nitrogen. Transactions of the American Institute of Mining and Metallurgical Engineers 188, 1261-1266.

Lütjering, G., Williams, J. C., 2003. Titanium: Engineering Materials and Processes, First ed. Manchester, UK, Springer, 1-356. 
Murray, J. L., 1987. Phase Diagrams of Binary Titanium Alloys, First ed, ASM International, $1-345$.

Niinomi, M., 1998. Mechanical Properties of Biomedical Titanium Alloys. Materials Science and Engineering A 243, 231-236.

Semlitsch, M., Staub, F., Weber H., 1985. Titanium-aluminium-niobium Alloy Development for Biocompatible, High Strength Surgical Implants. Biomedizinische Technik/Biomedical Engineering 30, 334-339.

Shi-bo, G., Xuan-hui, Q., Xin-bo, H., 2005. Influence of Sintering Temperature on Mechanical Properties of Ti-6A-4V Compacts by Metal Injection Molding. Materials Science Forum 475-479, 2639-2642.

van Loo, F. J. J., Rieck, G. D., 1973. Diffusion in the Titanium-aluminium System - I. Interdiffusion between Solid Al and Ti or Ti-Al alloys. Acta Metallurgica 21, 61-71. van Loo, F. J. J., Rieck, G. D., 1973. Diffusion in the Titanium-aluminium System - II. Interdiffusion in the Composition Range between 25 and 100 at.\% Ti. Acta Metallurgica $21,73-84$. 


\section{List of Figure Captions}

Figure 1. X-ray diffraction (XRD) patterns $\left(2 \theta=30-80^{\circ}\right)$ of the powders: a) elemental titanium and b) Ti-6Al-7Nb.

Figure 2. DTA heating curves for elemental titanium and the Ti-6Al-7Nb alloy.

Figure 3. Dilatometric curves for elemental titanium and the Ti-6Al-7Nb alloys.

Figure 4. Microstructural evolution with the sintering temperature of elemental titanium produced by $\mathrm{P} \& \mathrm{~S}$ : a) $900^{\circ} \mathrm{C}$, b) $1000^{\circ} \mathrm{C}$, c) $1100^{\circ} \mathrm{C}$, d) $1200^{\circ} \mathrm{C}$, e) $1300^{\circ} \mathrm{C}$ and f) $1400^{\circ} \mathrm{C}$.

Figure 5. Microstructural evolution with the sintering temperature of the Ti-6Al-7Nb alloy produced by master alloy addition and by $\mathrm{P} \& \mathrm{~S}$ : a) $900^{\circ} \mathrm{C}$, b) $1000^{\circ} \mathrm{C}$, c) $1100^{\circ} \mathrm{C}$, d) $1200^{\circ} \mathrm{C}$, e) $1300^{\circ} \mathrm{C}$ and f) $1400^{\circ} \mathrm{C}$.

Figure 6. Compositional change near a master alloy particle in the Ti-6Al-7Nb alloy sintered at $900^{\circ} \mathrm{C}$ determined by EDS (distance from each position: $10 \mu \mathrm{m}$ ).

Figure 7. Details of the Kirkendall pores observed in the master alloy particles and induced by the faster diffusion of aluminium in titanium compared to niobium.

Figure 8. XRD patterns of specimens sintered at $900^{\circ} \mathrm{C}, 1100^{\circ} \mathrm{C}$ and $1400^{\circ} \mathrm{C}$ : a) $\mathrm{HDH}$ elemental titanium and b) blended elemental Ti-6Al-7Nb alloy.

Figure 9. Relative density versus sintering temperature for elemental titanium and for the Ti$6 \mathrm{Al}-7 \mathrm{Nb}$ alloy.

Figure 10. Representative load-deflection curves of elemental titanium and the blended elemental Ti-6Al-7Nb samples sintered at: a) $900^{\circ} \mathrm{C}$, b) $1100^{\circ} \mathrm{C}$ and c) $1300^{\circ} \mathrm{C}$.

Figure 11. Variation of the yield strength, determined by three-point bending tests, of elemental titanium and the Ti-6Al-7Nb samples as a function of the sintering temperature. 
Figure 12. Hardness as a function of the sintering temperature for $\mathrm{P} \& \mathrm{~S}$ elemental titanium and the Ti-6Al-7Nb samples.

\section{List of Tables}

Table 1. Characteristics of the starting powders employed for the production of the Ti-6Al$7 \mathrm{Nb}$ alloy (suppliers' specifications).

Table 2. Details from the analyses of the DTA curves presented in Figure 2.

Table 3. Details of the features detected during the dilatometric analysis of elemental titanium and the Ti-6Al-7Nb alloy.

Table 4. Chemical composition of the Ti-6Al-7Nb alloy (data obtained by EDS) as a function of the sintering temperature.

Table 5. EDS chemical composition as a function of the sintering temperature for the alpha and the beta phase of the Ti-6Al-7Nb alloy.

Table 6. Maximum bending strength and flexural strain of elemental titanium and the Ti-6Al$7 \mathrm{Nb} \mathrm{P} \& \mathrm{~S}$ samples.

Table 7. Contents of oxygen and nitrogen measured on elemental titanium and Ti-6Al-7Nb P\&S samples. 
Table 1. Characteristics of the starting powders employed for the production of the Ti-6Al$7 \mathrm{Nb}$ alloy (suppliers' specifications).

\begin{tabular}{|c|c|c|c|}
\hline Feature & Elemental Ti & Nb:Al:Ti & Elemental Al \\
\hline \hline Composition [wt.\%] & $>99.7$ & $60: 35: 5$ & $>99$ \\
\hline Maximum particle size [ $\mu \mathrm{m}]$ & $<75$ & $<800$ & $<150$ \\
\hline Particle morphology & Angular & Granules & Spherical \\
\hline Melting point $\left[{ }^{\circ} \mathrm{C}\right]$ & 1667 & - & 660 \\
\hline
\end{tabular}

Table 2. Details from the analyses of the DTA curves presented in Figure 2.

\begin{tabular}{|c|c|c|c|c|}
\hline \multirow{2}{*}{ Alloy } & $\begin{array}{c}\text { Onset } \\
\text { temperature } \\
{\left[{ }^{\circ} \mathbf{C}\right]}\end{array}$ & $\begin{array}{c}\text { Top of the } \\
\text { peak }\left[{ }^{\circ} \mathbf{C}\right]\end{array}$ & Reaction & $\begin{array}{c}\text { Nominal beta } \\
\text { transus }\left[{ }^{\circ} \mathbf{C}\right]\end{array}$ \\
\hline Elemental $\mathrm{Ti}$ & 875.5 & 904.7 & $\alpha \rightarrow \beta$ & $882 \pm 2$ \\
\hline \multirow{2}{*}{ Ti-6Al-7Nb } & 325.8 & 339.6 & Wax elimination & \multirow{2}{*}{$1010 \pm 15$} \\
\cline { 2 - 4 } & 654.6 & 659.3 & Ti-Al reaction & \\
\cline { 2 - 4 } & 876.1 & 901.6 & $\alpha \rightarrow \beta$ & \\
\hline
\end{tabular}

Table 3. Details of the features detected during the dilatometric analysis of elemental titanium and the Ti-6Al-7Nb alloy.

\begin{tabular}{|c|c|c|}
\hline Alloy & $\begin{array}{c}\text { Maximum } \\
\text { shrinkage [\%] }\end{array}$ & $\begin{array}{c}\text { Onset } \\
\text { temperature }\left[{ }^{\circ} \mathbf{C}\right]\end{array}$ \\
\hline \hline Elemental $\mathrm{Ti}$ & -5.70 & 870.7 \\
\hline Ti-6Al-7Nb & -7.44 & 812.4 \\
\hline
\end{tabular}

Table 4. Chemical composition of the Ti-6Al-7Nb alloy (data obtained by EDS) as a function of the sintering temperature.

\begin{tabular}{|c|c|c|c|}
\hline Temperature $\left[{ }^{\mathbf{0}} \mathbf{C}\right.$ ] & \multicolumn{3}{|c|}{ Composition [wt.\%] } \\
\hline & $\mathrm{Ti}$ & $\mathrm{Al}$ & $\mathrm{Nb}$ \\
\hline 1100 & 88.13 & 4.85 & 7.02 \\
\hline 1200 & 87.41 & 5.75 & 6.84 \\
\hline 1300 & 87.15 & 5.72 & 7.13 \\
\hline 1400 & 87.15 & 5.85 & 7.00 \\
\hline
\end{tabular}

Table 5. EDS chemical composition as a function of the sintering temperature for the alpha and the beta phase of the Ti-6Al-7Nb alloy.

\begin{tabular}{|c|c|c|c|c|c|c|}
\hline Temperature [ ${ }^{\mathbf{0}} \mathbf{C}$ ] & \multicolumn{3}{|c|}{ Composition $\boldsymbol{\alpha}$-phase [at.\%] } & \multicolumn{3}{c|}{ Composition $\boldsymbol{\beta}$-phase [at.\%] } \\
\hline & $\mathrm{Ti}$ & $\mathrm{Al}$ & $\mathrm{Nb}$ & $\mathrm{Ti}$ & $\mathrm{Al}$ & $\mathrm{Nb}$ \\
\hline \hline 1100 & 89.59 & 8.71 & 1.70 & 82.65 & 3.97 & 13.38 \\
\hline
\end{tabular}




\begin{tabular}{|c|c|c|c|c|c|c|}
\hline 1200 & 87.56 & 10.64 & 1.81 & 82.10 & 4.66 & 13.25 \\
\hline 1300 & 86.72 & 11.16 & 2.12 & 80.86 & 5.27 & 13.87 \\
\hline 1400 & 88.70 & 9.42 & 1.88 & 81.04 & 6.14 & 12.83 \\
\hline
\end{tabular}

Table 6. Maximum bending strength and flexural strain of elemental titanium and the Ti-6Al$7 \mathrm{Nb} \mathrm{P} \& \mathrm{~S}$ samples.

\begin{tabular}{|c|c|c|c|}
\hline \multicolumn{2}{|c|}{ Material } & Elemental Ti & Ti-6 Al-7Nb \\
\hline \hline \multirow{4}{*}{$\begin{array}{c}\text { Maximum bending } \\
\text { strength [MPa] }\end{array}$} & $900^{\circ} \mathrm{C}$ & 877 & 582 \\
\cline { 2 - 4 } & $1000^{\circ} \mathrm{C}$ & 1071 & 778 \\
\cline { 2 - 4 } & $1100^{\circ} \mathrm{C}$ & 1154 & 1203 \\
\cline { 2 - 4 } & $1200^{\circ} \mathrm{C}$ & 1203 & 1350 \\
\cline { 2 - 4 } & $1300^{\circ} \mathrm{C}$ & 1171 & 1228 \\
\cline { 2 - 4 } & $1400^{\circ} \mathrm{C}$ & 1199 & 658 \\
\hline \hline \multirow{5}{*}{ Flexural strain [\%] } & $900^{\circ} \mathrm{C}$ & 1.21 & 0.72 \\
\cline { 2 - 4 } & $1000^{\circ} \mathrm{C}$ & 2.47 & 0.75 \\
\cline { 2 - 4 } & $1100^{\circ} \mathrm{C}$ & 2.79 & 0.95 \\
\cline { 2 - 4 } & $1200^{\circ} \mathrm{C}$ & 3.31 & 2.13 \\
\cline { 2 - 4 } & $1300^{\circ} \mathrm{C}$ & 4.11 & 1.80 \\
\cline { 2 - 4 } & $1400^{\circ} \mathrm{C}$ & 1.09 & 1.01 \\
\hline
\end{tabular}

Table 7. Contents of oxygen and nitrogen measured on elemental titanium and Ti-6Al-7Nb P\&S samples.

\begin{tabular}{|c|c|c|c|}
\hline \multicolumn{2}{|c|}{ Material } & Elemental Ti & $T i-6 \mathrm{Al}-7 \mathrm{Nb}$ \\
\hline \hline \multirow{4}{*}{ Oxygen content [\%] } & $900^{\circ} \mathrm{C}$ & $0.37 \pm 0.01$ & $0.41 \pm 0.01$ \\
\cline { 2 - 4 } & $1000^{\circ} \mathrm{C}$ & $0.37 \pm 0.04$ & $0.40 \pm 0.02$ \\
\cline { 2 - 4 } & $1100^{\circ} \mathrm{C}$ & $0.32 \pm 0.01$ & $0.40 \pm 0.03$ \\
\cline { 2 - 4 } & $1200^{\circ} \mathrm{C}$ & $0.38 \pm 0.02$ & $0.43 \pm 0.02$ \\
\cline { 2 - 4 } & $1300^{\circ} \mathrm{C}$ & $0.33 \pm 0.04$ & $0.45 \pm 0.01$ \\
\cline { 2 - 4 } & $1400^{\circ} \mathrm{C}$ & $0.43 \pm 0.06$ & $0.47 \pm 0.03$ \\
\hline \hline \multirow{5}{*}{ Nitrogen content $[\%]$} & $900^{\circ} \mathrm{C}$ & $0.027 \pm 0.004$ & $0.022 \pm 0.001$ \\
\cline { 2 - 4 } & $1000^{\circ} \mathrm{C}$ & $0.029 \pm 0.006$ & $0.025 \pm 0.003$ \\
\cline { 2 - 4 } & $1100^{\circ} \mathrm{C}$ & $0.029 \pm 0.004$ & $0.027 \pm 0.001$ \\
\cline { 2 - 4 } & $1200^{\circ} \mathrm{C}$ & $0.025 \pm 0.006$ & $0.029 \pm 0.004$ \\
\cline { 2 - 4 } & $1300^{\circ} \mathrm{C}$ & $0.027 \pm 0.008$ & $0.029 \pm 0.001$ \\
\cline { 2 - 4 } & $1400^{\circ} \mathrm{C}$ & $0.031 \pm 0.004$ & $0.032 \pm 0.004$ \\
\hline
\end{tabular}


$>$ The suitability of the master alloy addition approach to produce the Ti-6Al-7Nb alloy is studied. > Study of the diffusion processes that take place to obtain a homogeneous microstructure. $>$ Microstructural evolution of the materials with the processing temperature. $>$ Analysis of the bending properties of powder metallurgy elemental titanium and Ti-6Al-7Nb alloy. 


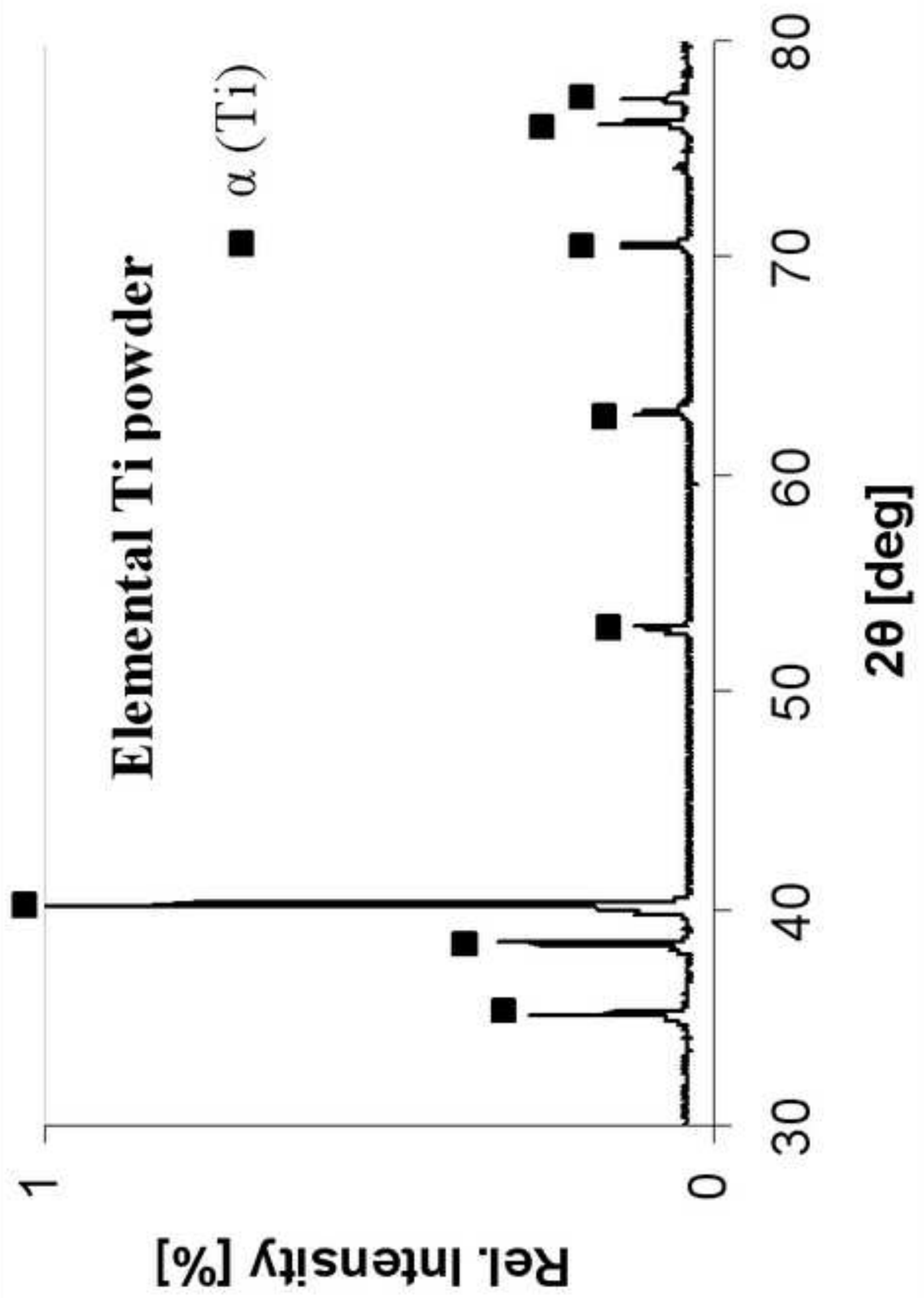




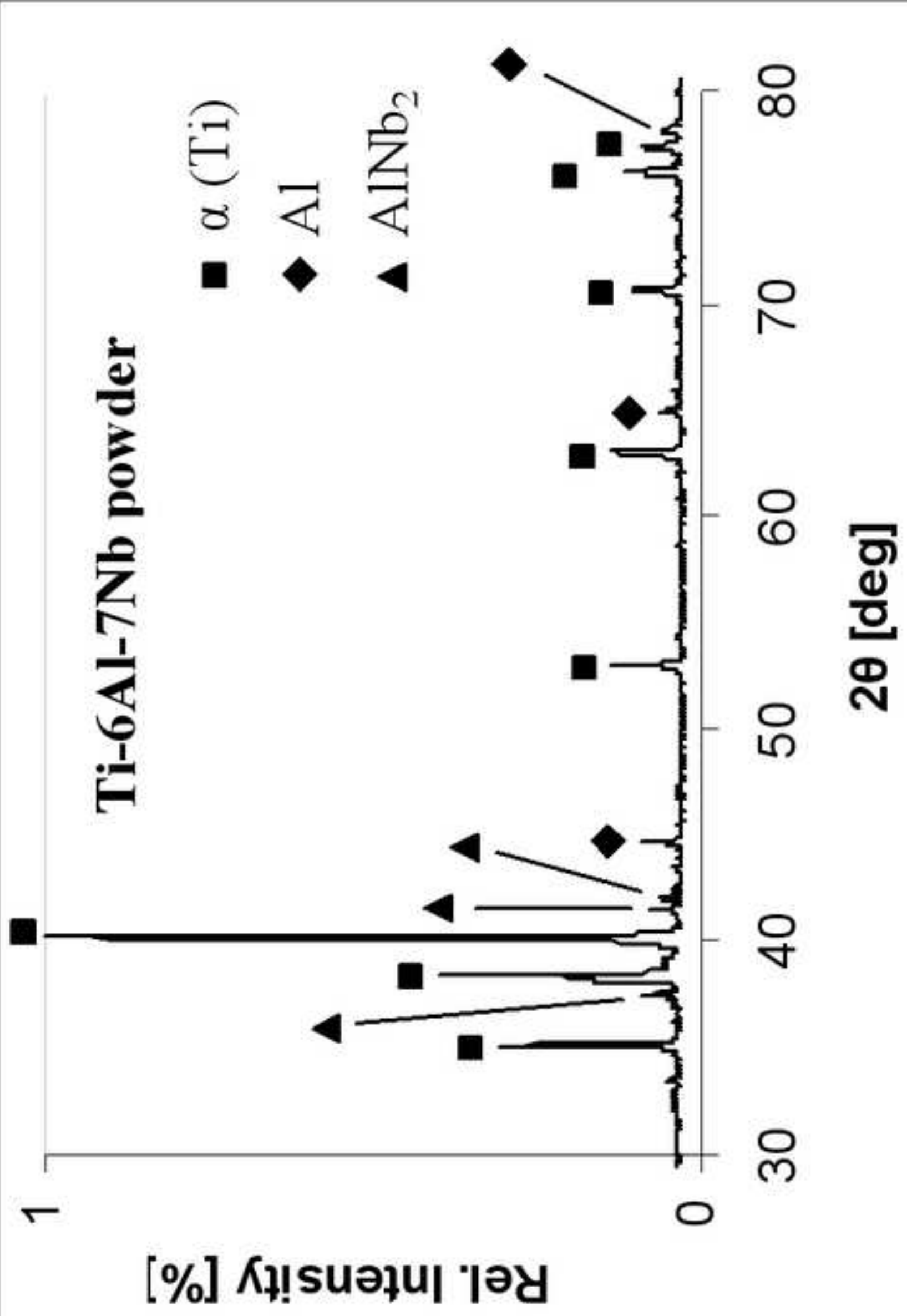




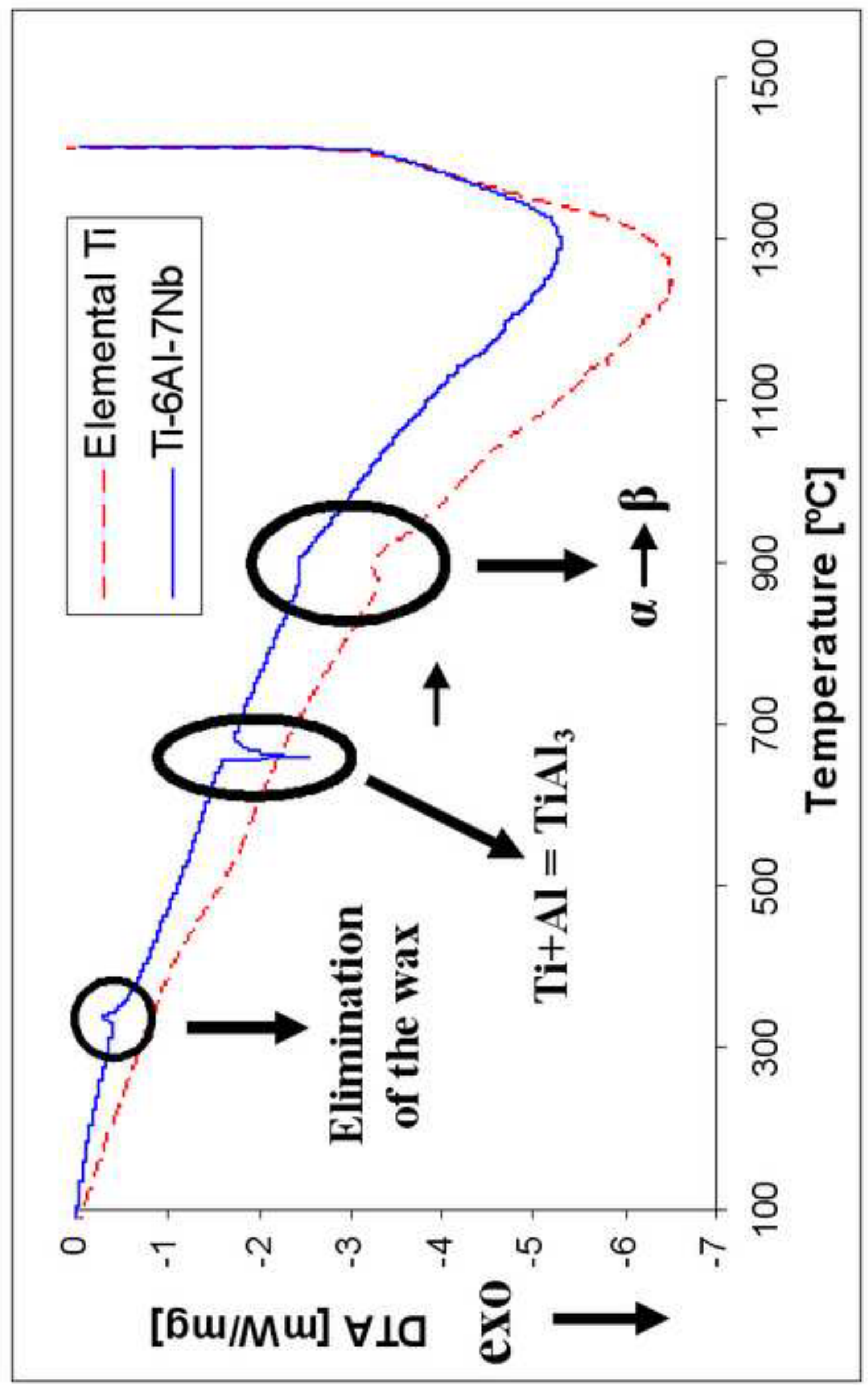




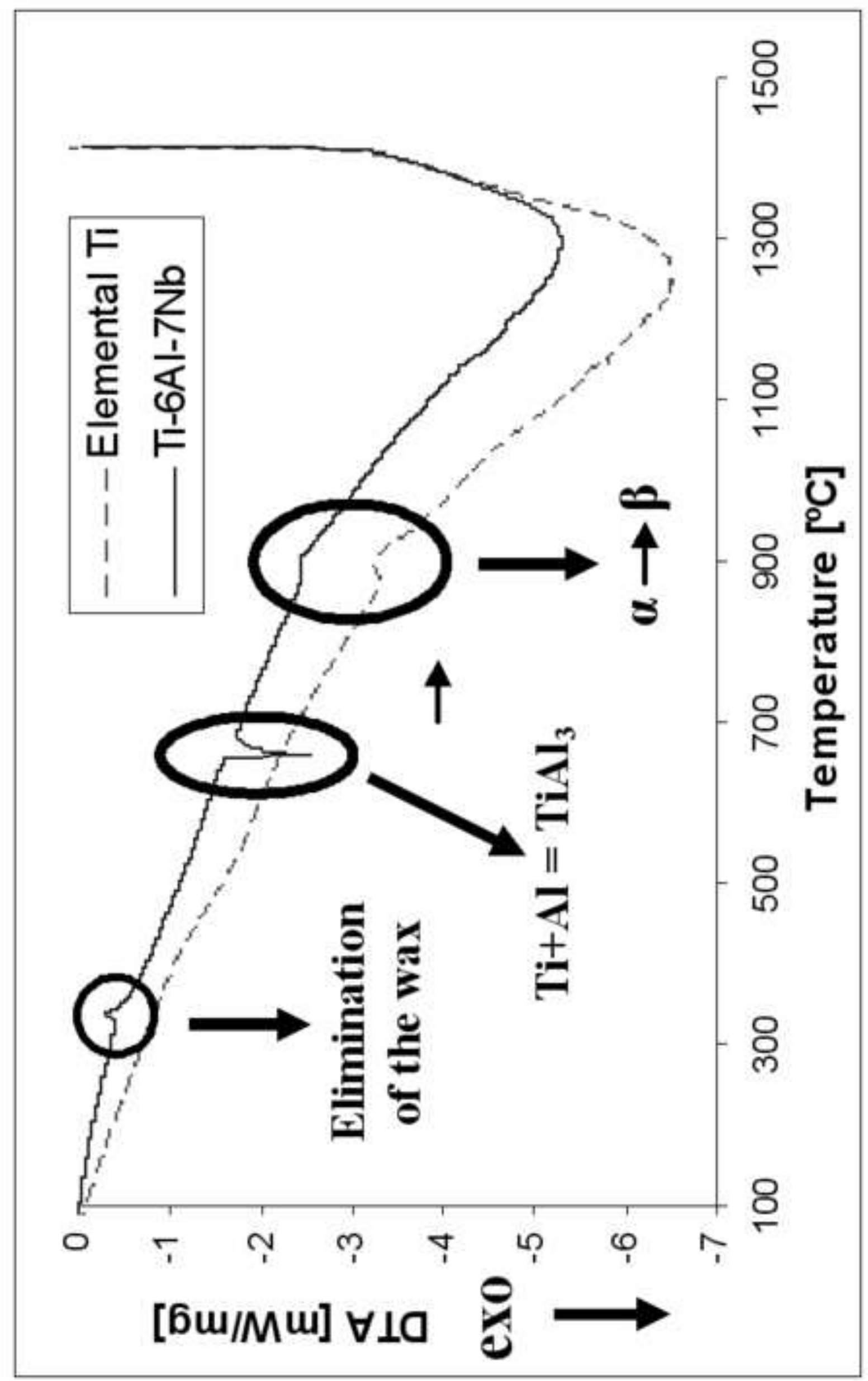




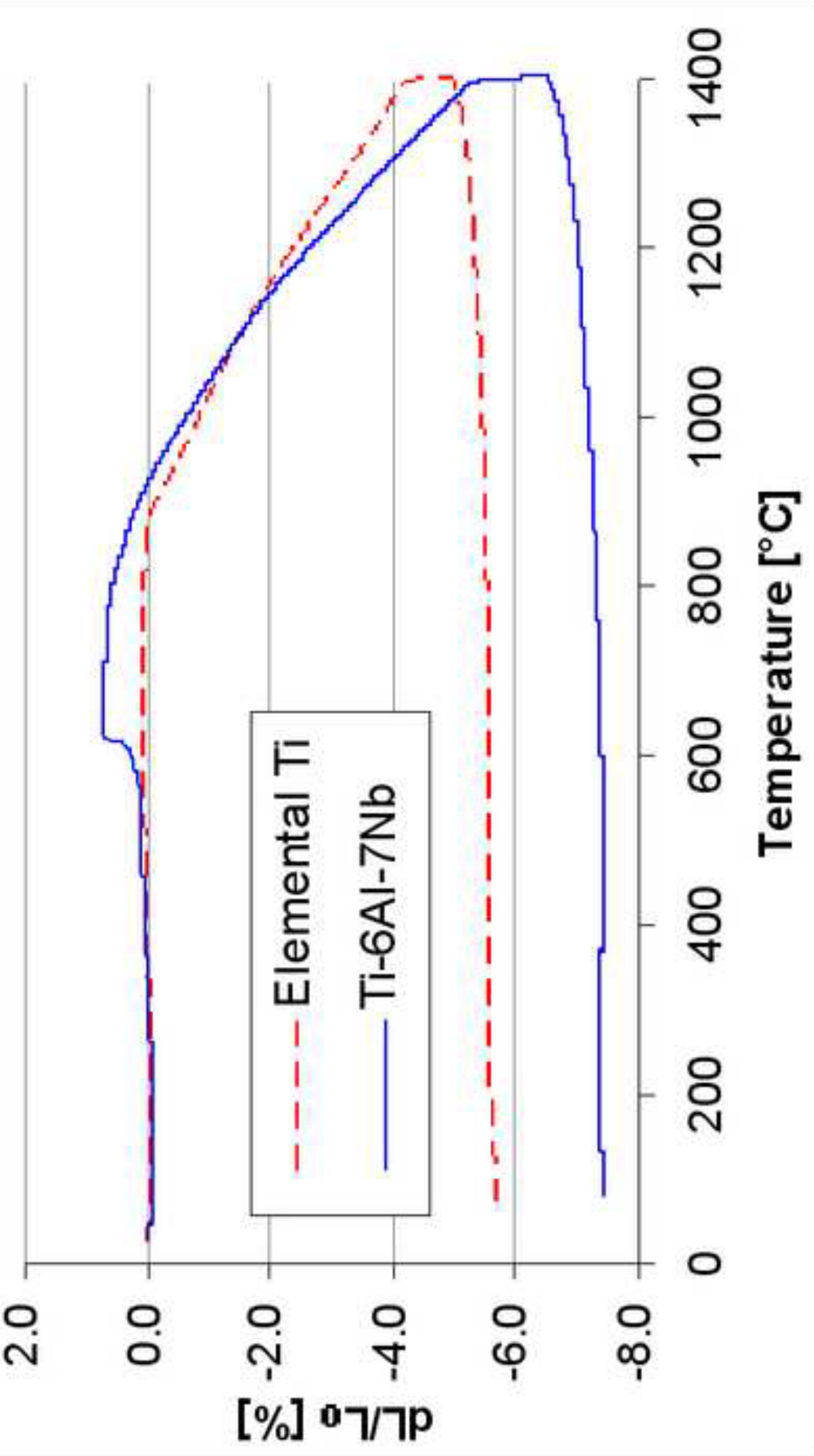




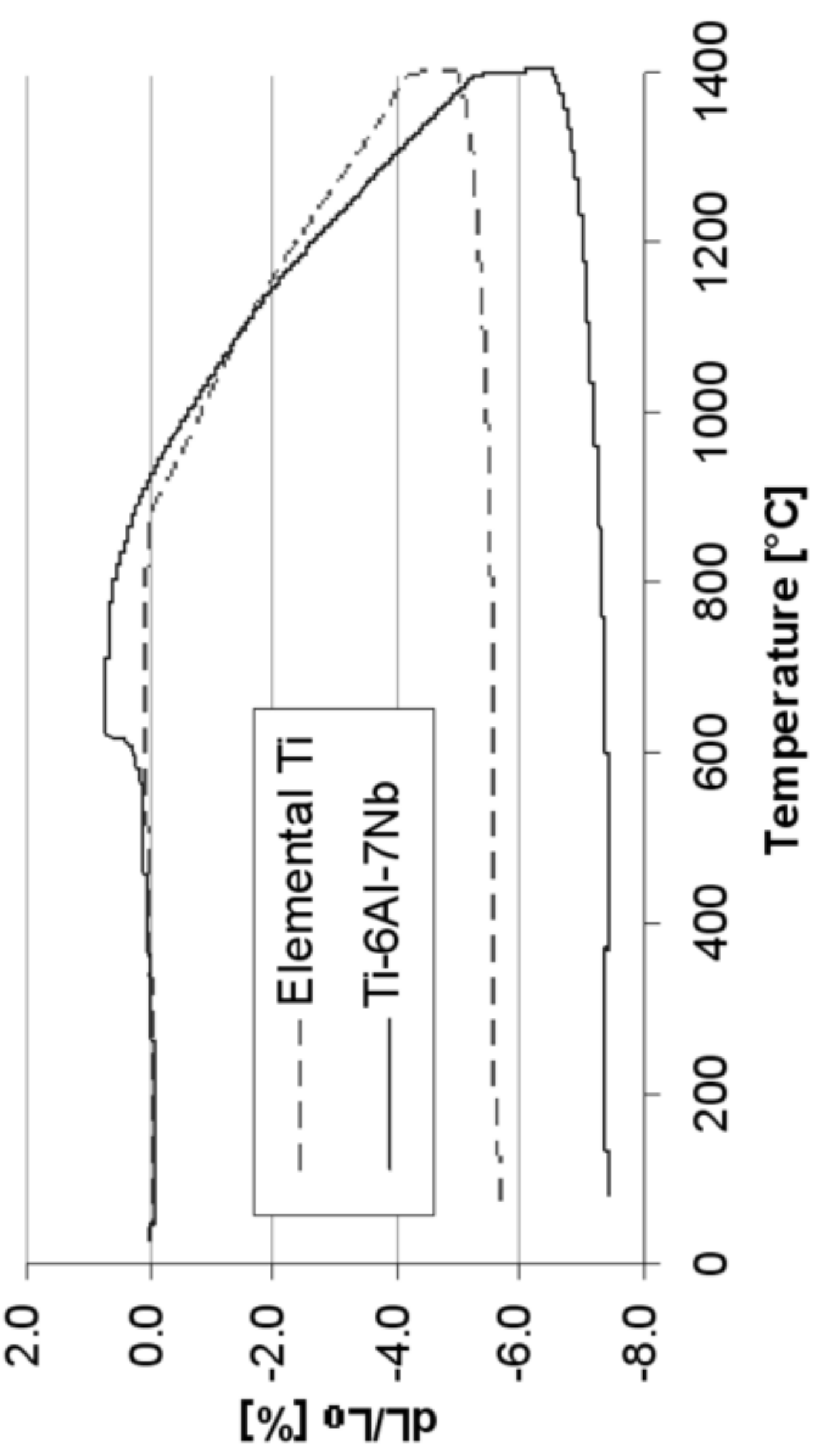

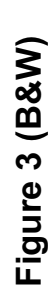




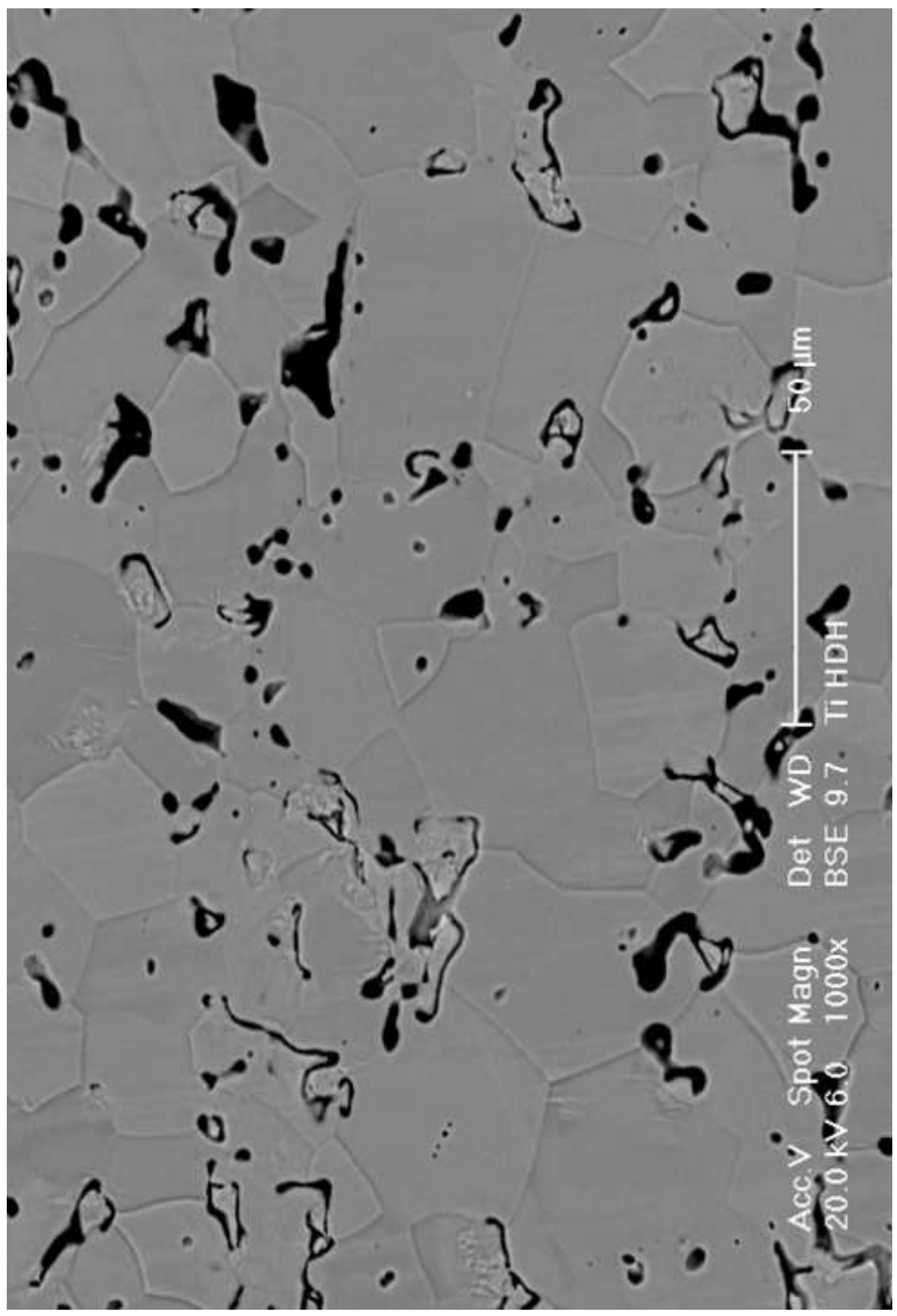




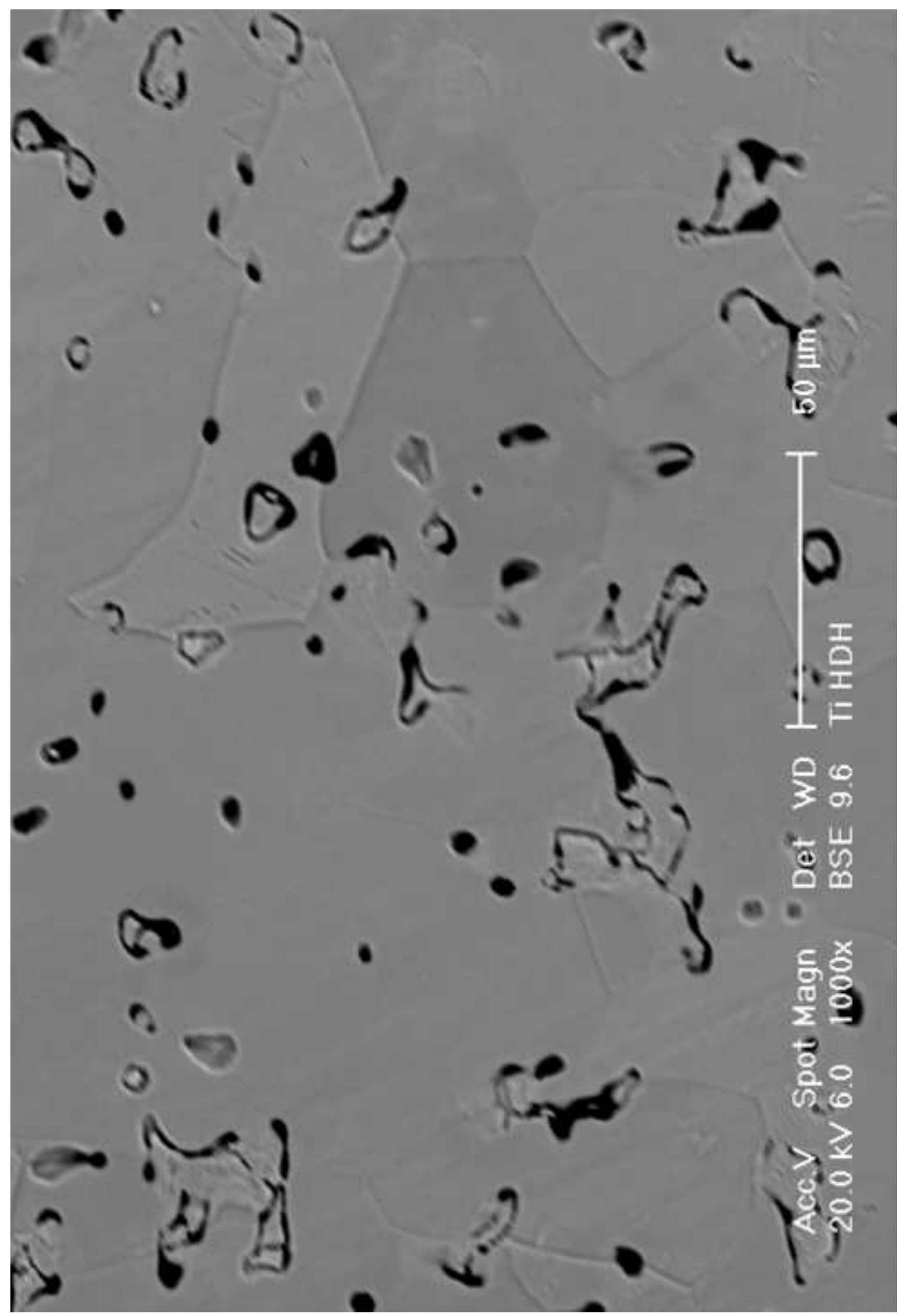




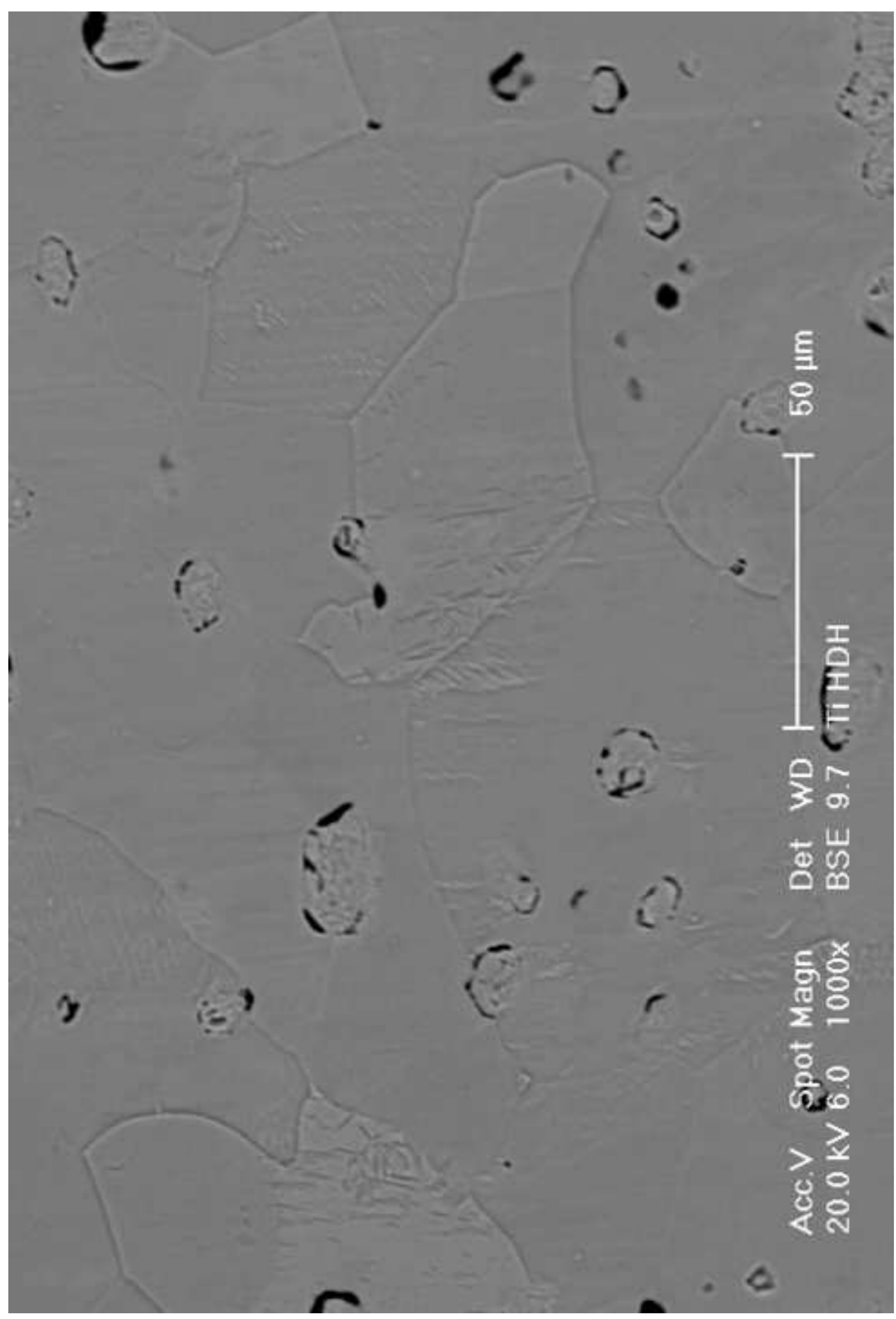




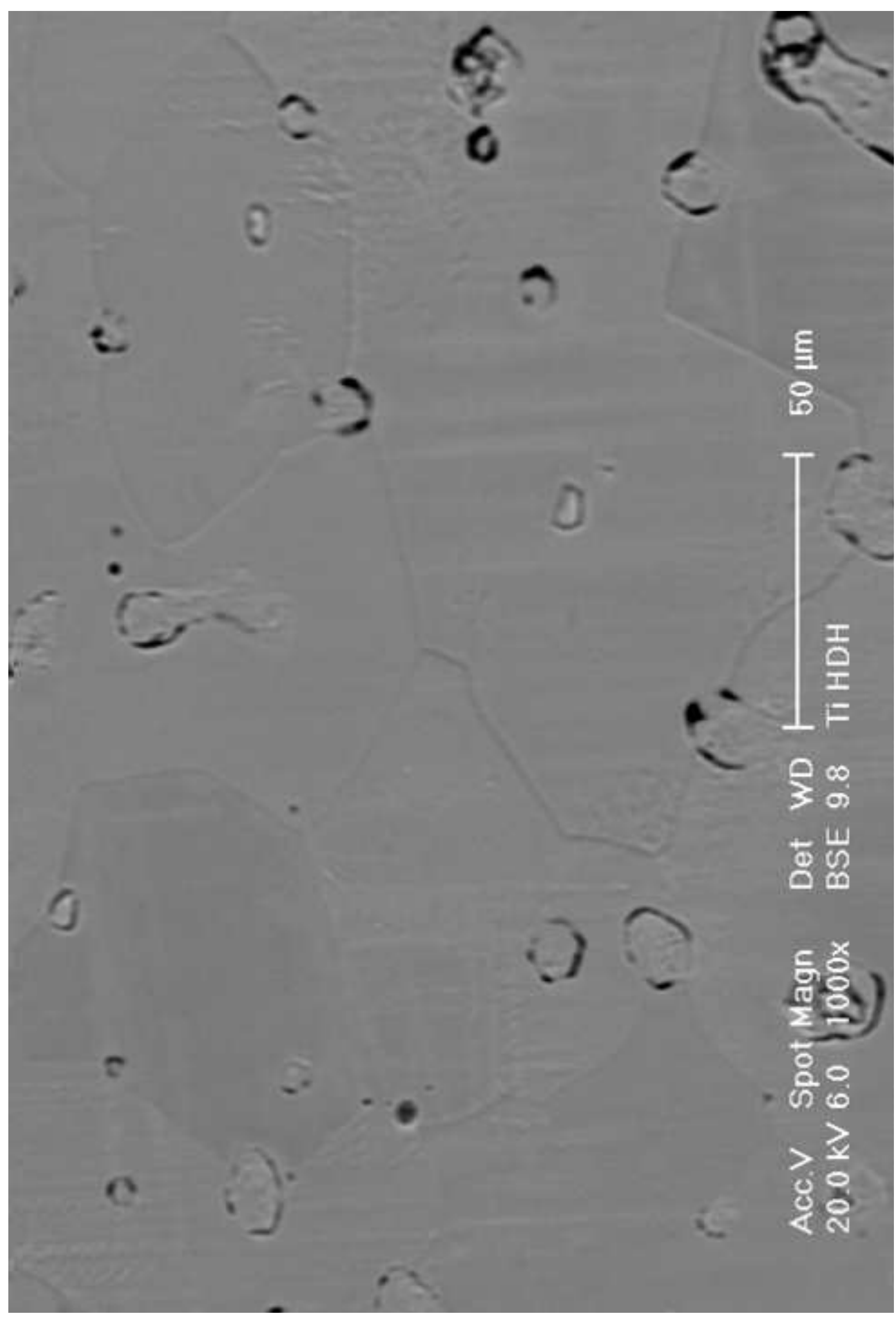




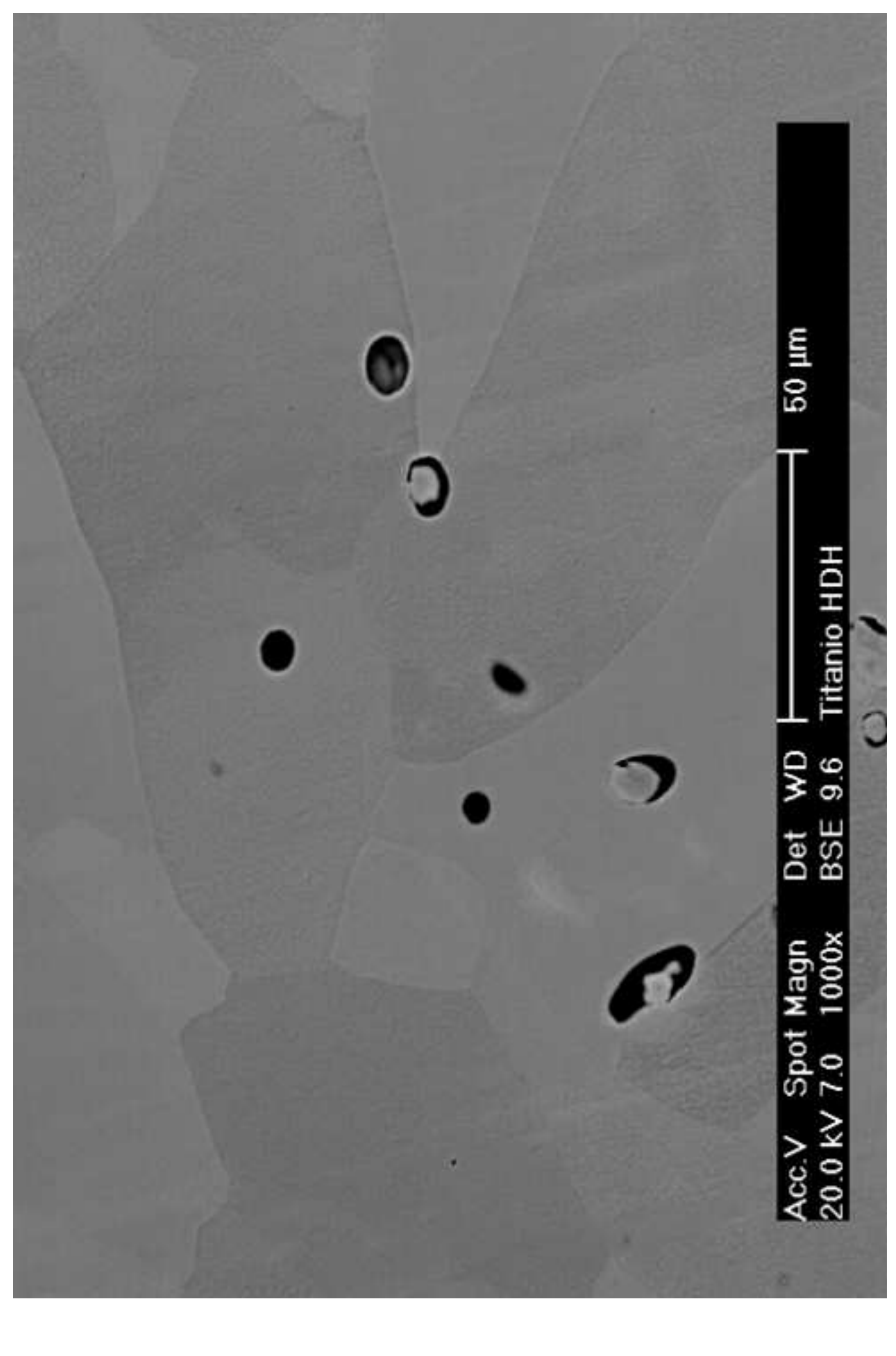




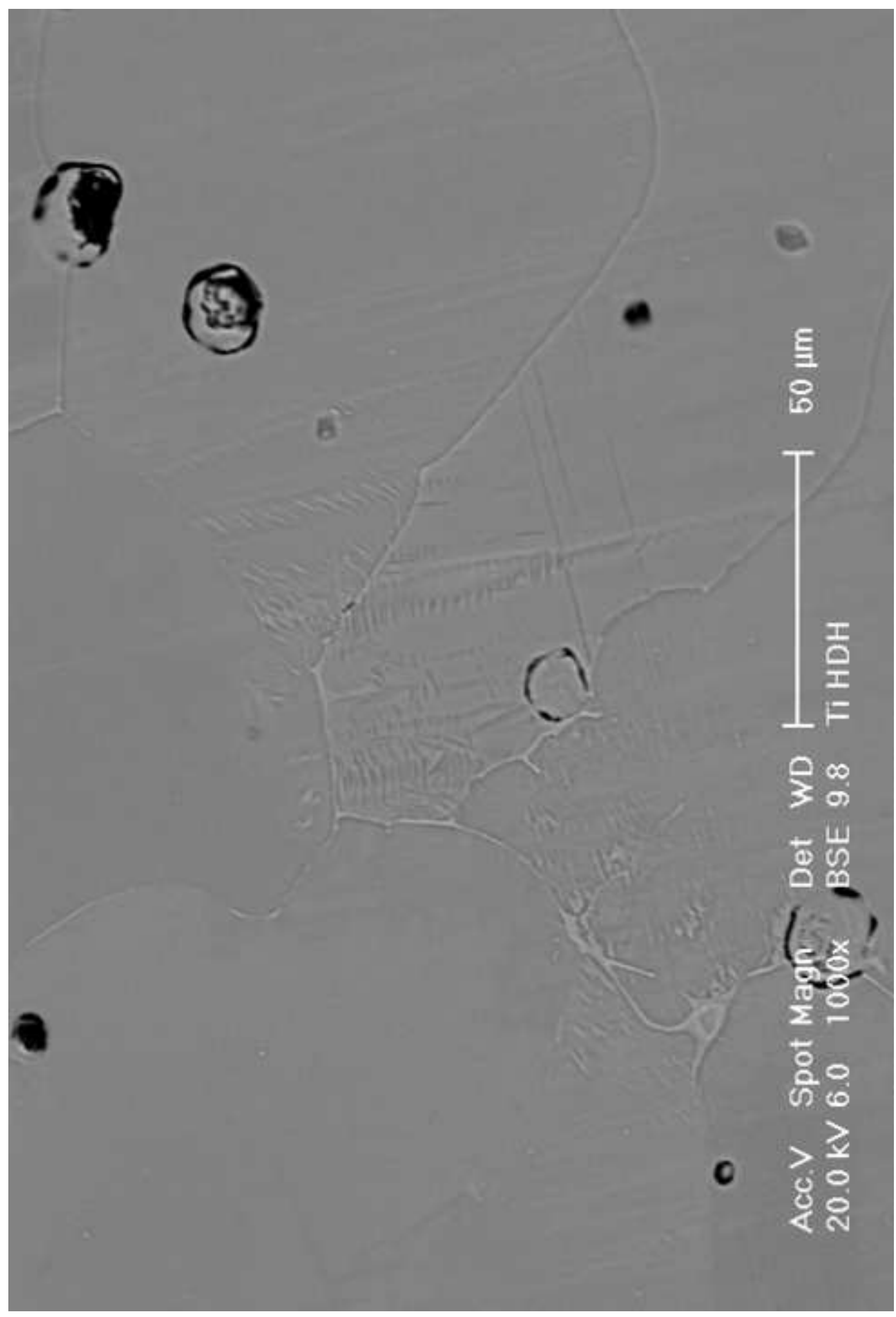

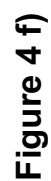




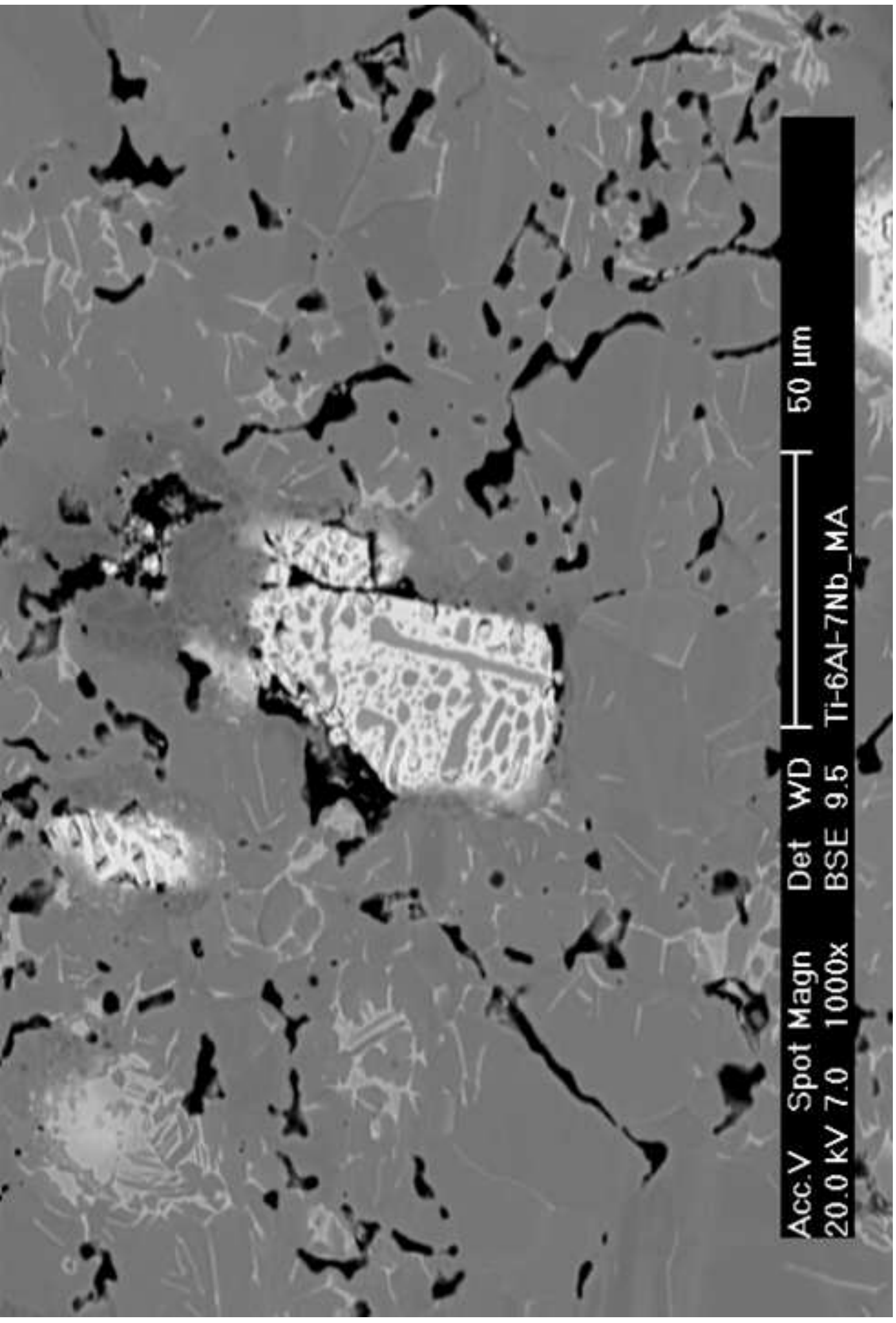




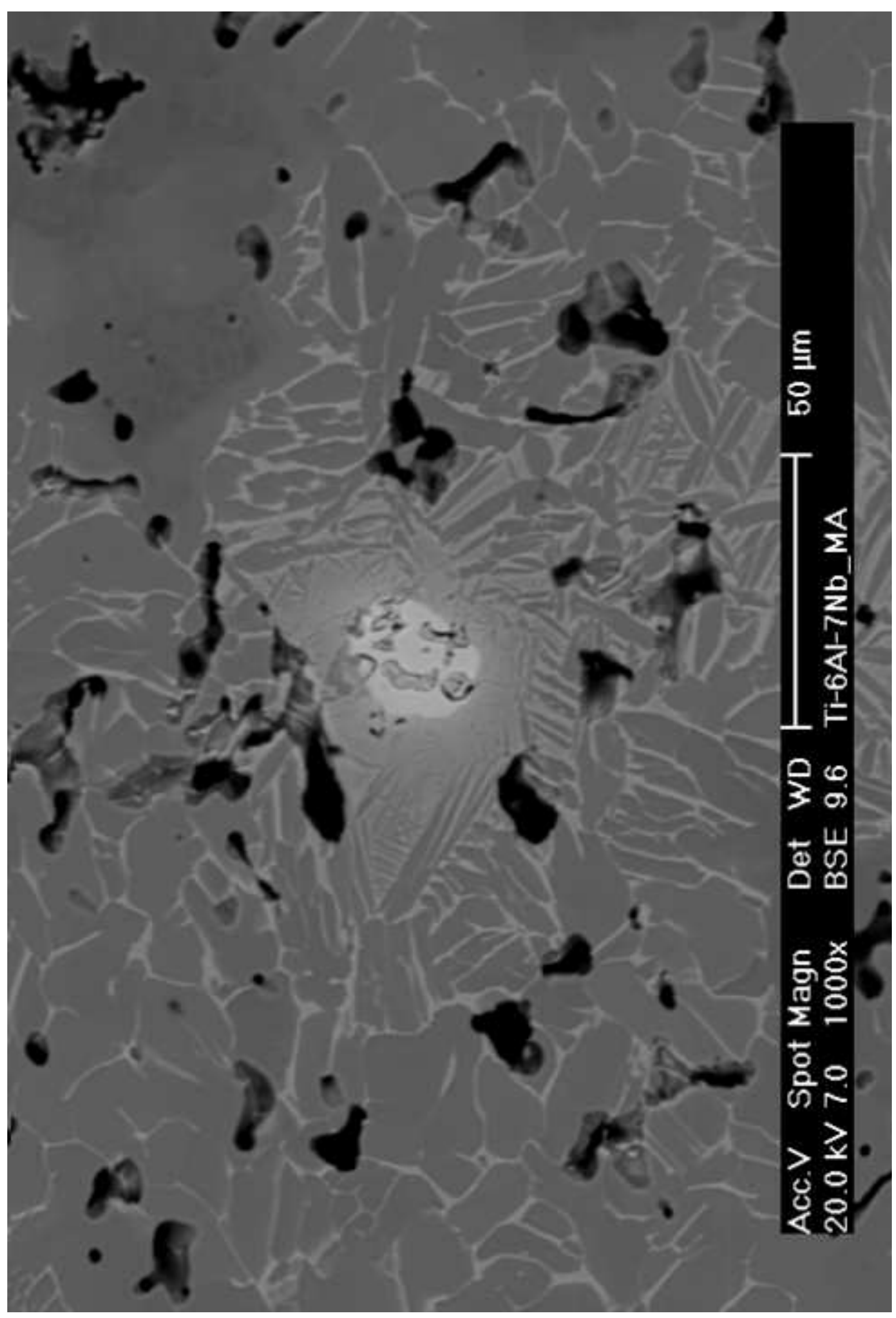




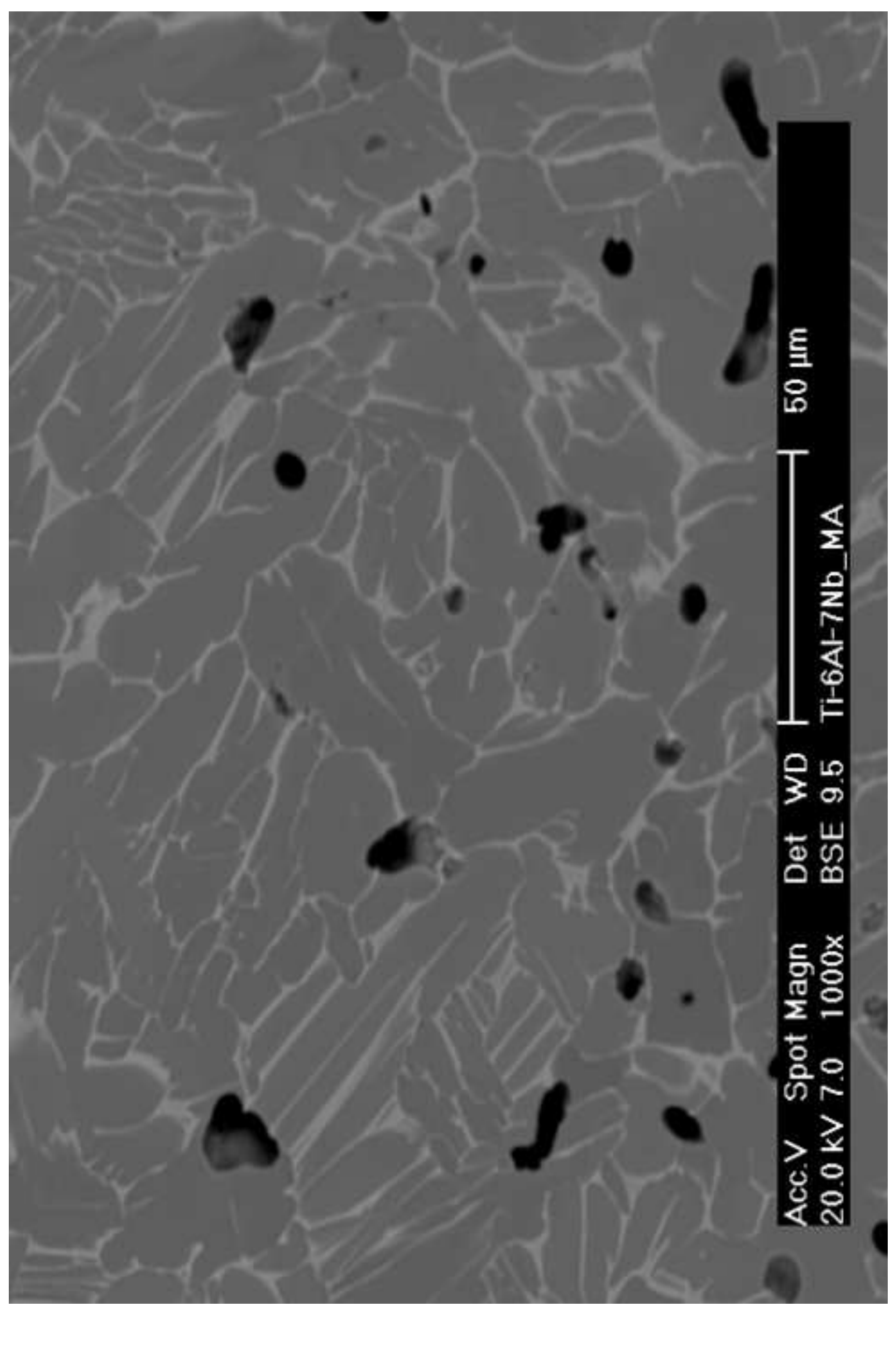




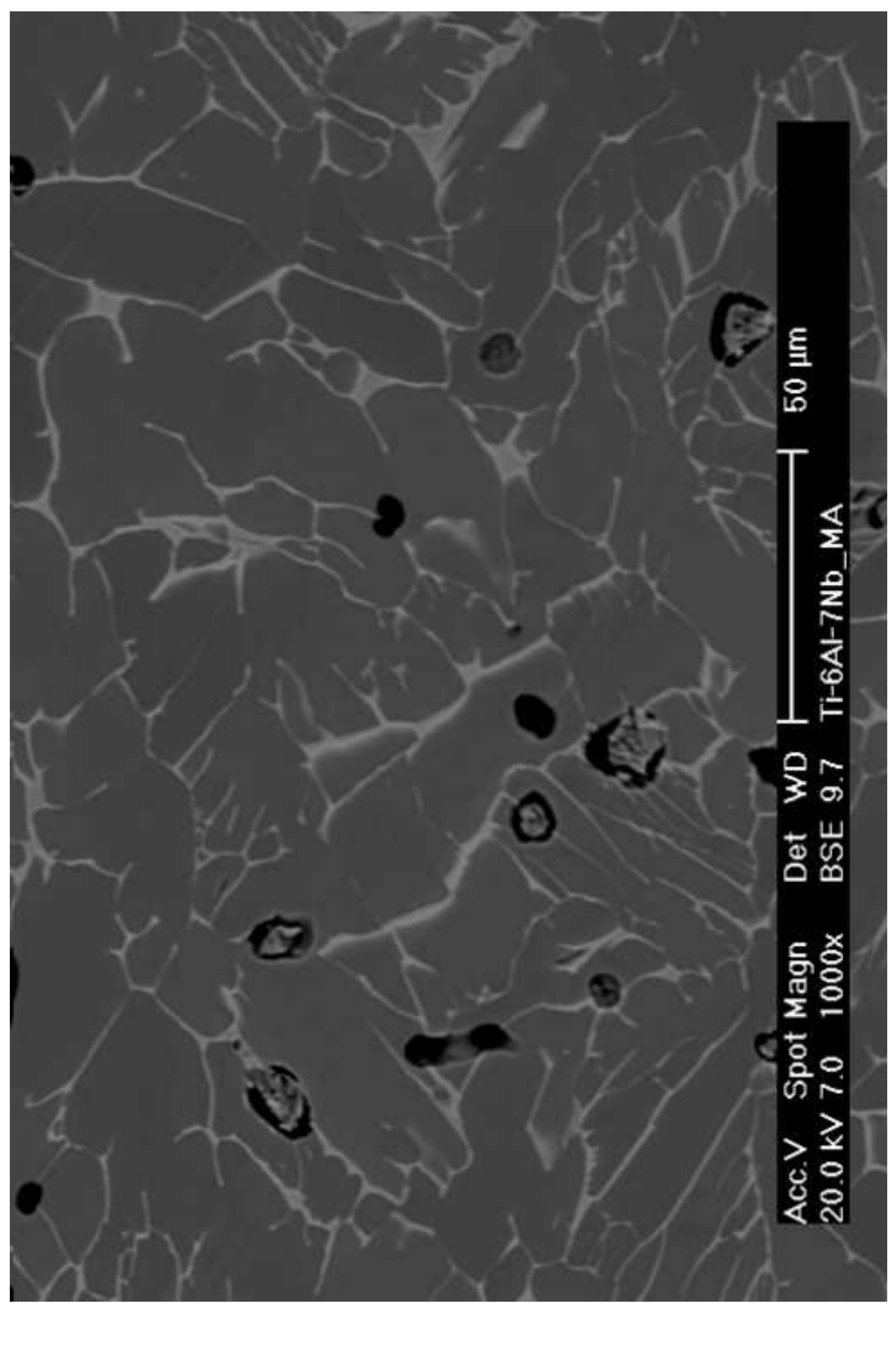




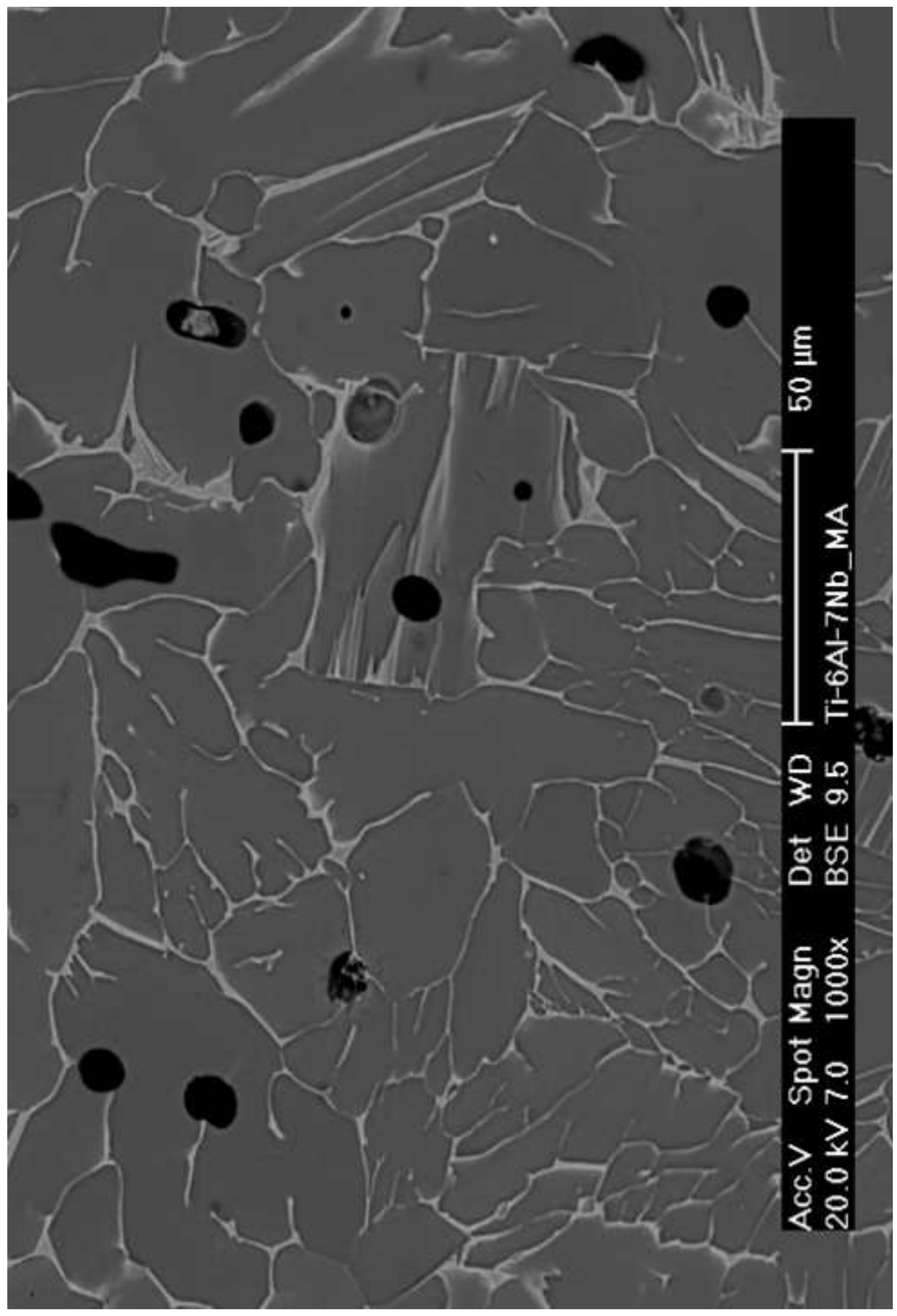




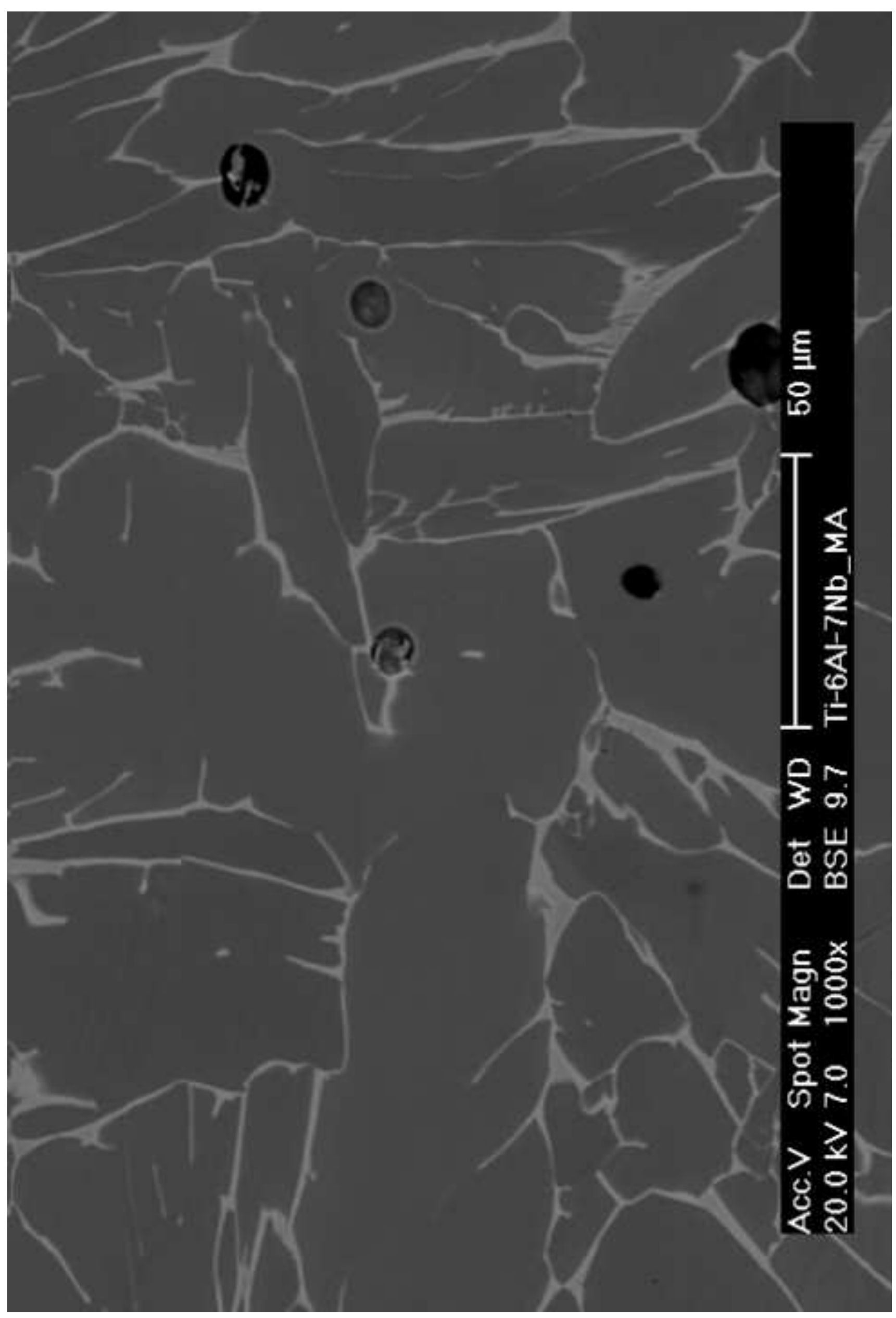




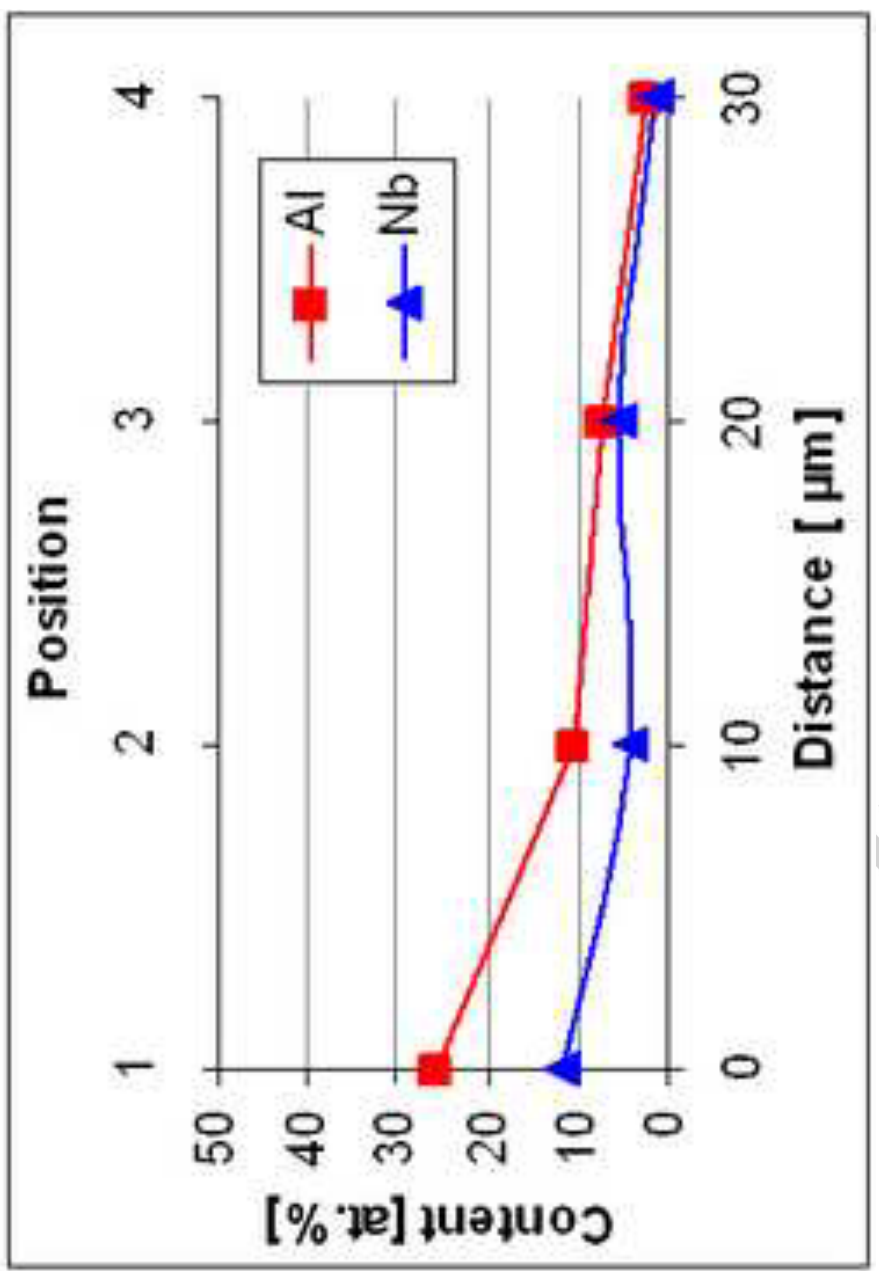

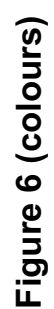

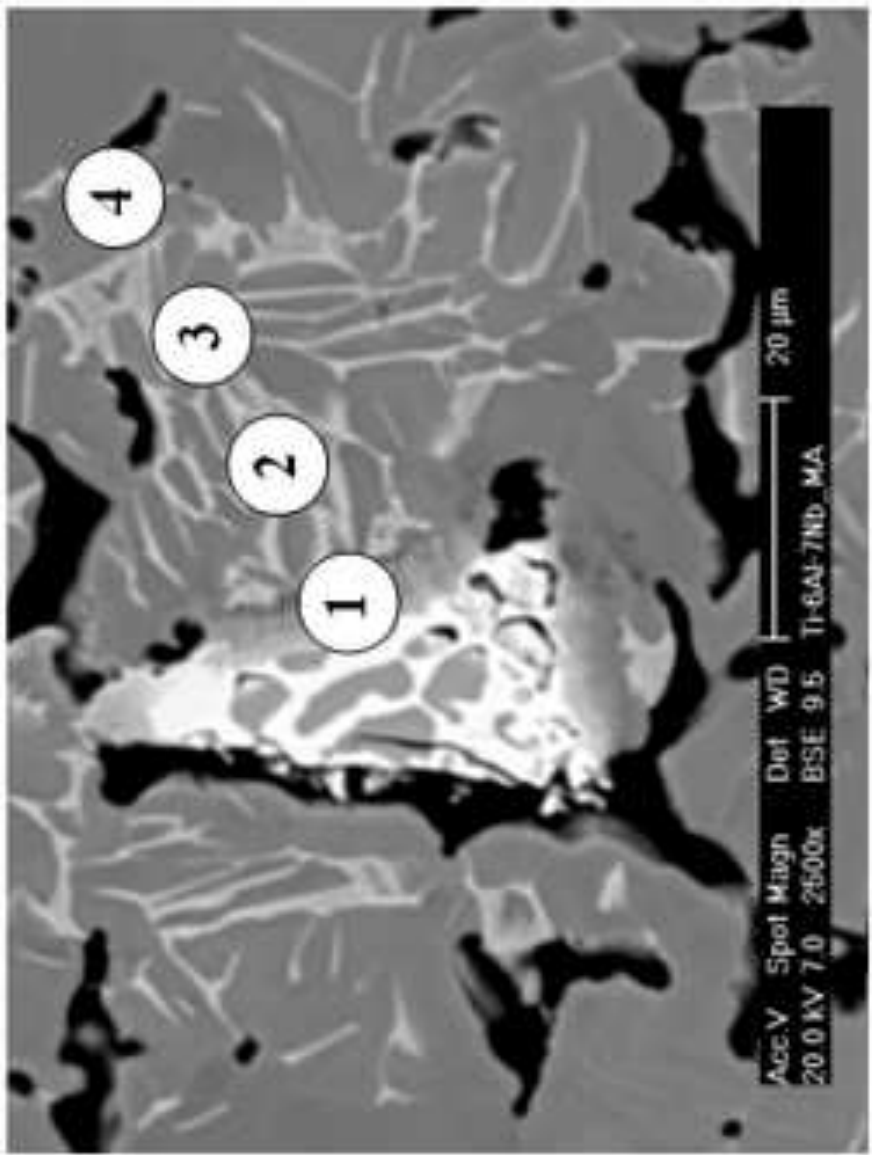




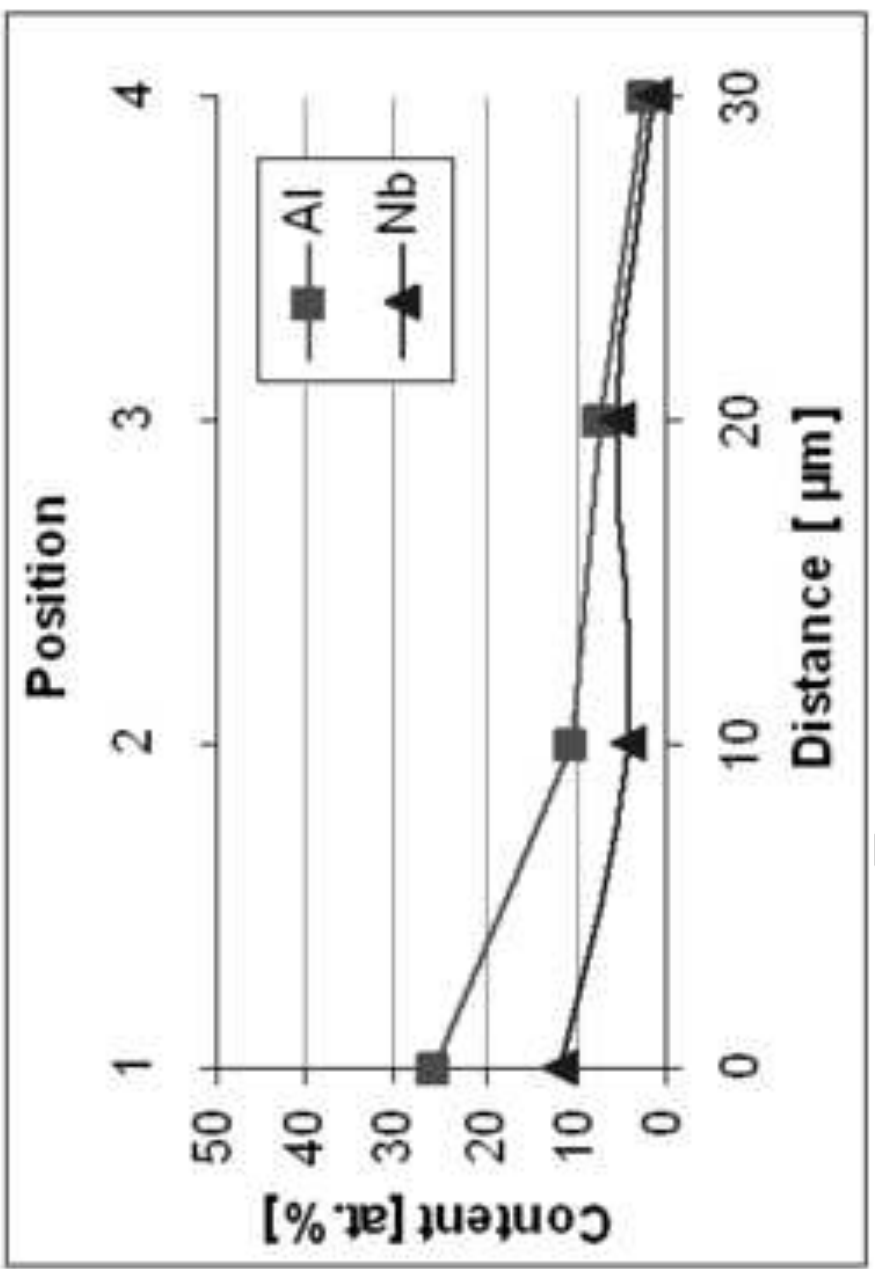

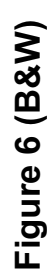

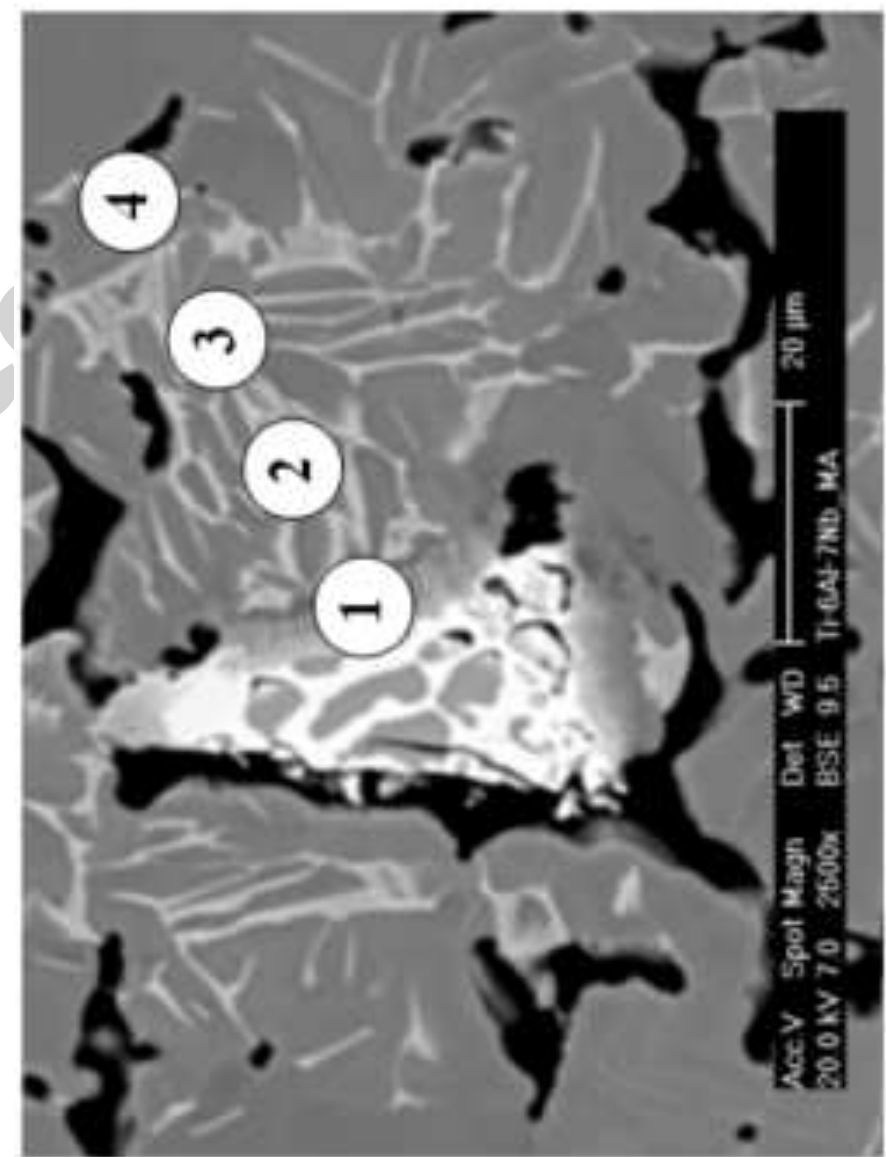




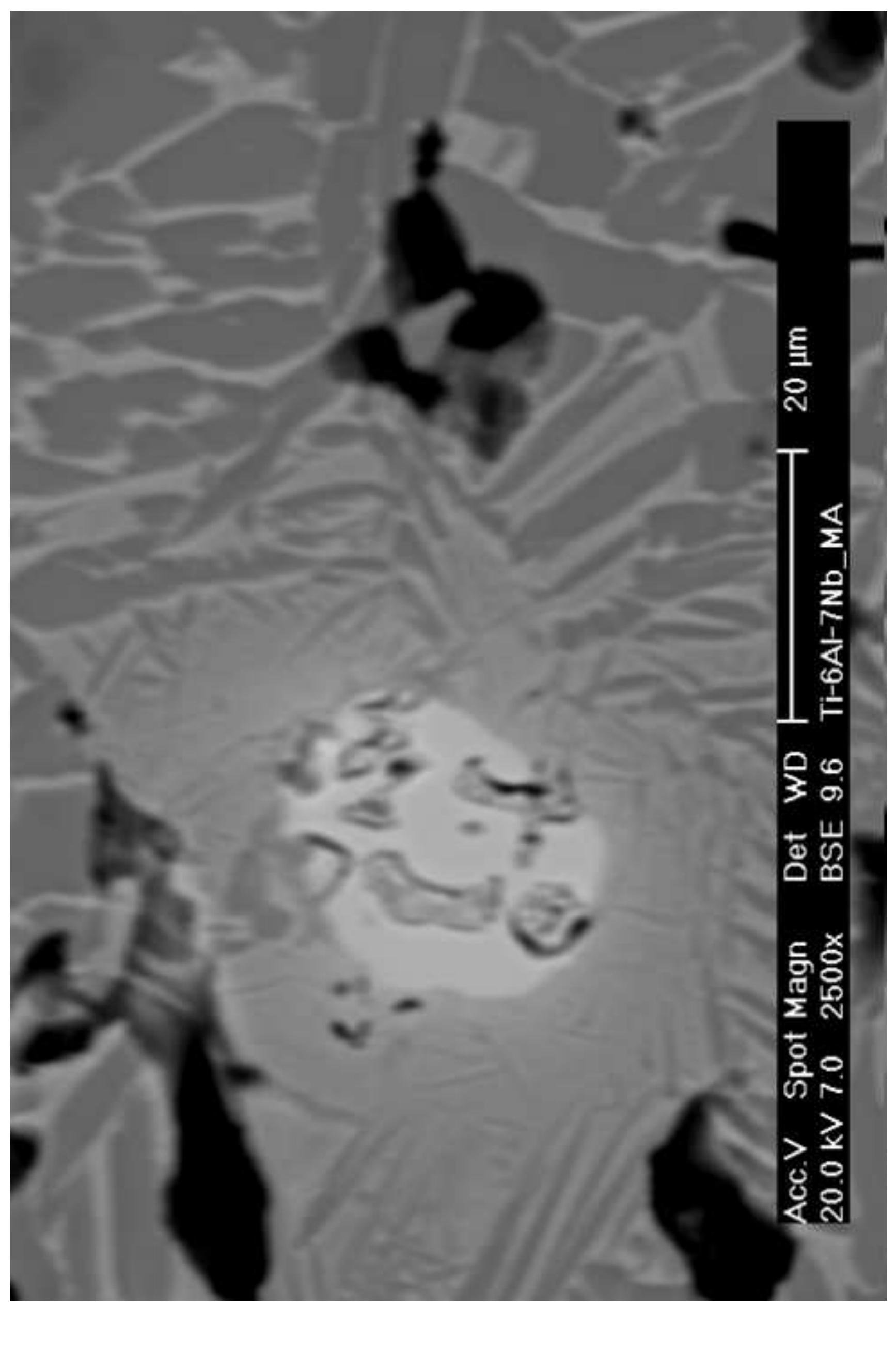




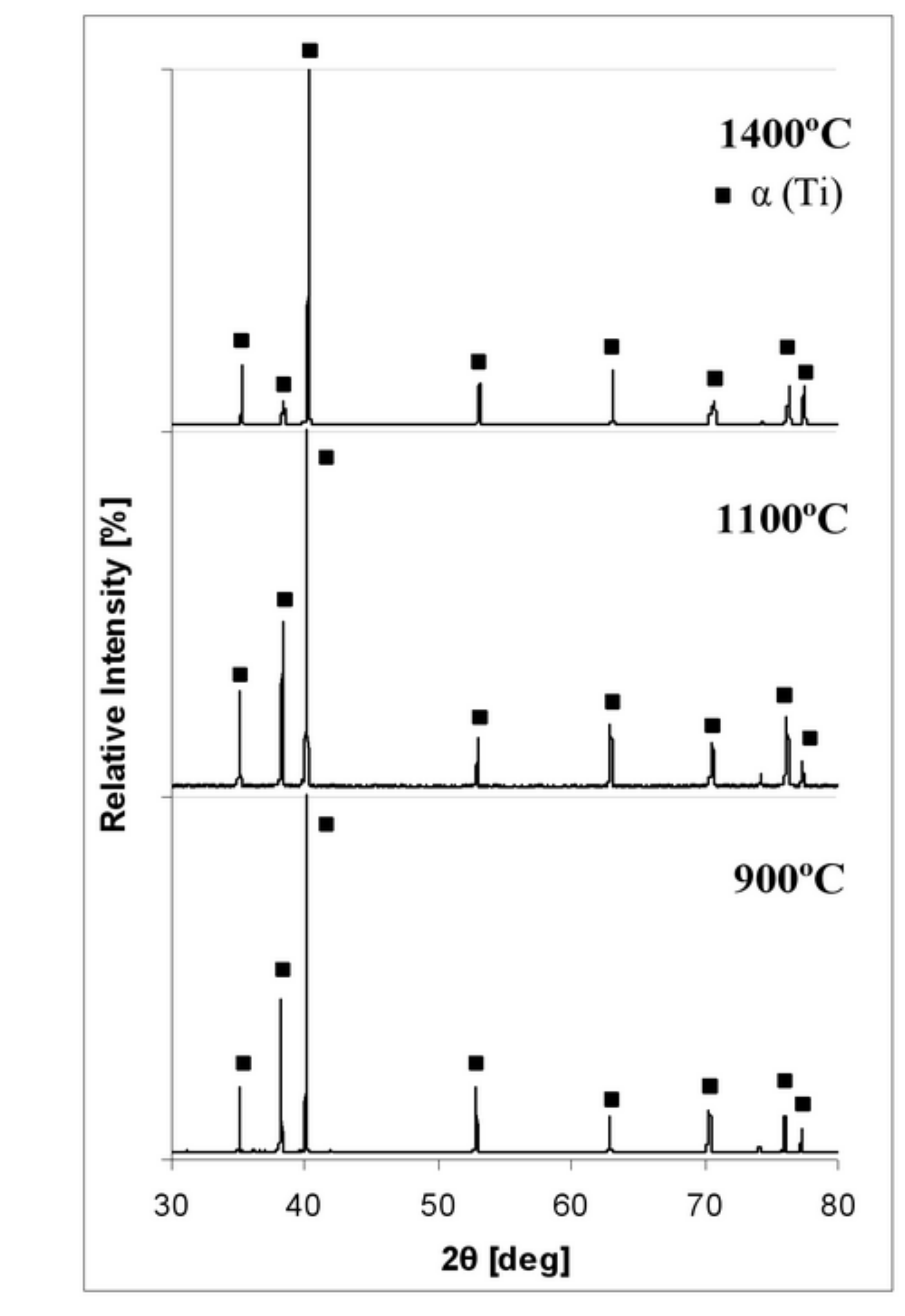

Figure 8 a)
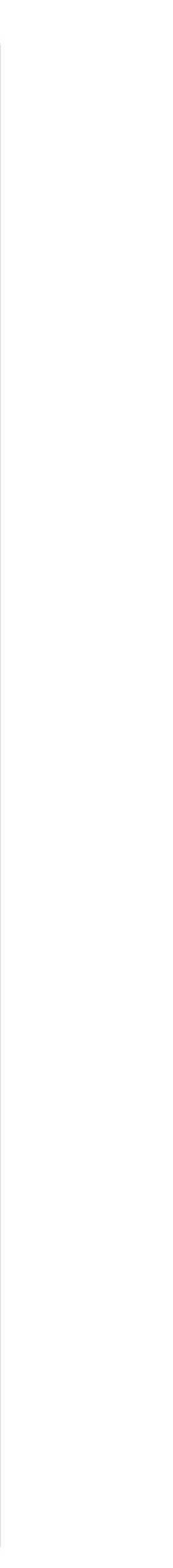


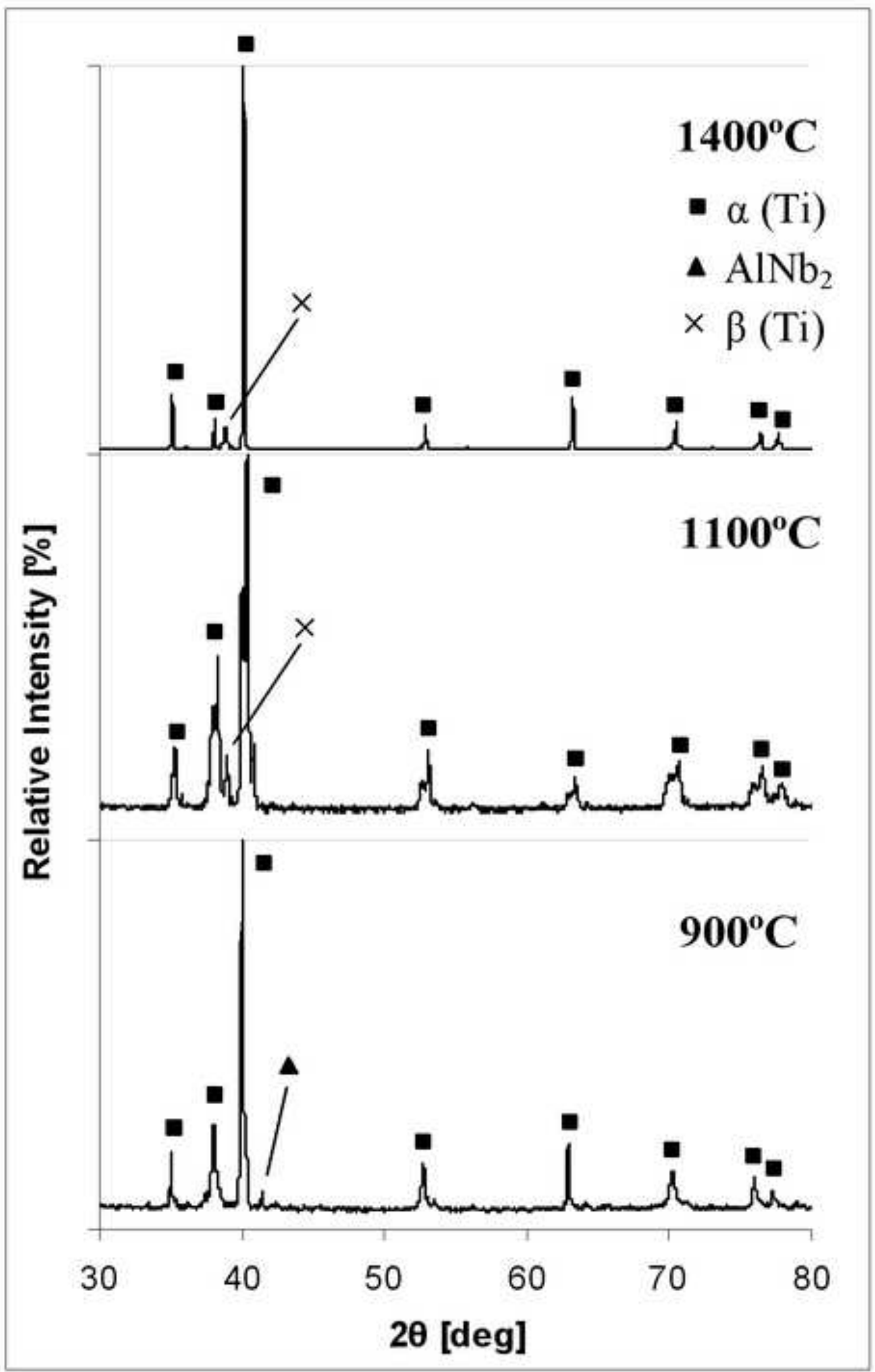

Figure 8 b)

\section{$1400^{\circ} \mathrm{C}$}

- $\alpha$ (Ti)

- $\mathrm{AlNb}_{2}$

$\times \beta(\mathrm{Ti})$

$1100^{\circ} \mathrm{C}$

$900^{\circ} \mathrm{C}$

$\begin{array}{cccrrr}30 & 40 & 50 & 60 & 70 & 80 \\ & & \mathbf{2 \theta} \text { [deg] }\end{array}$




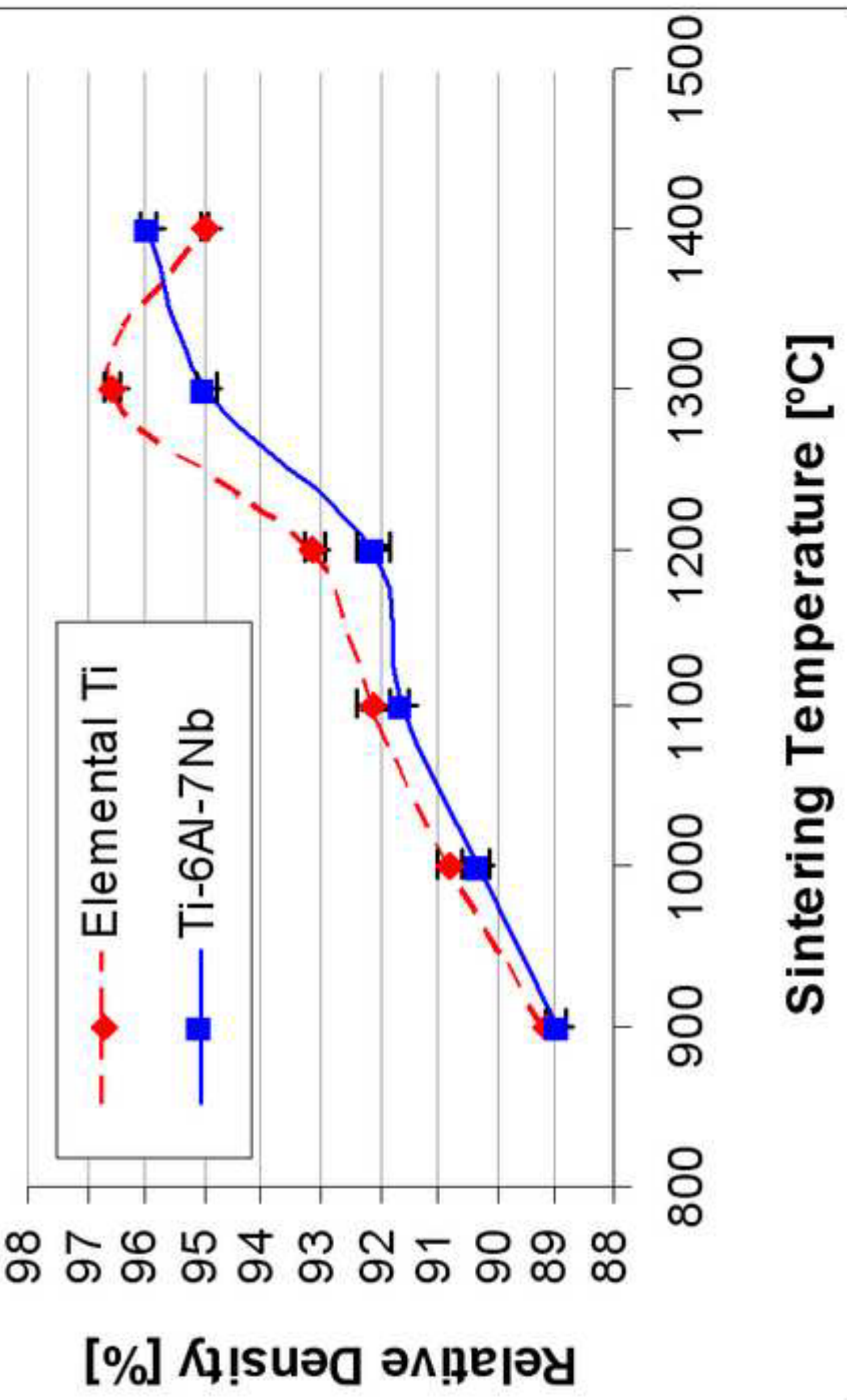




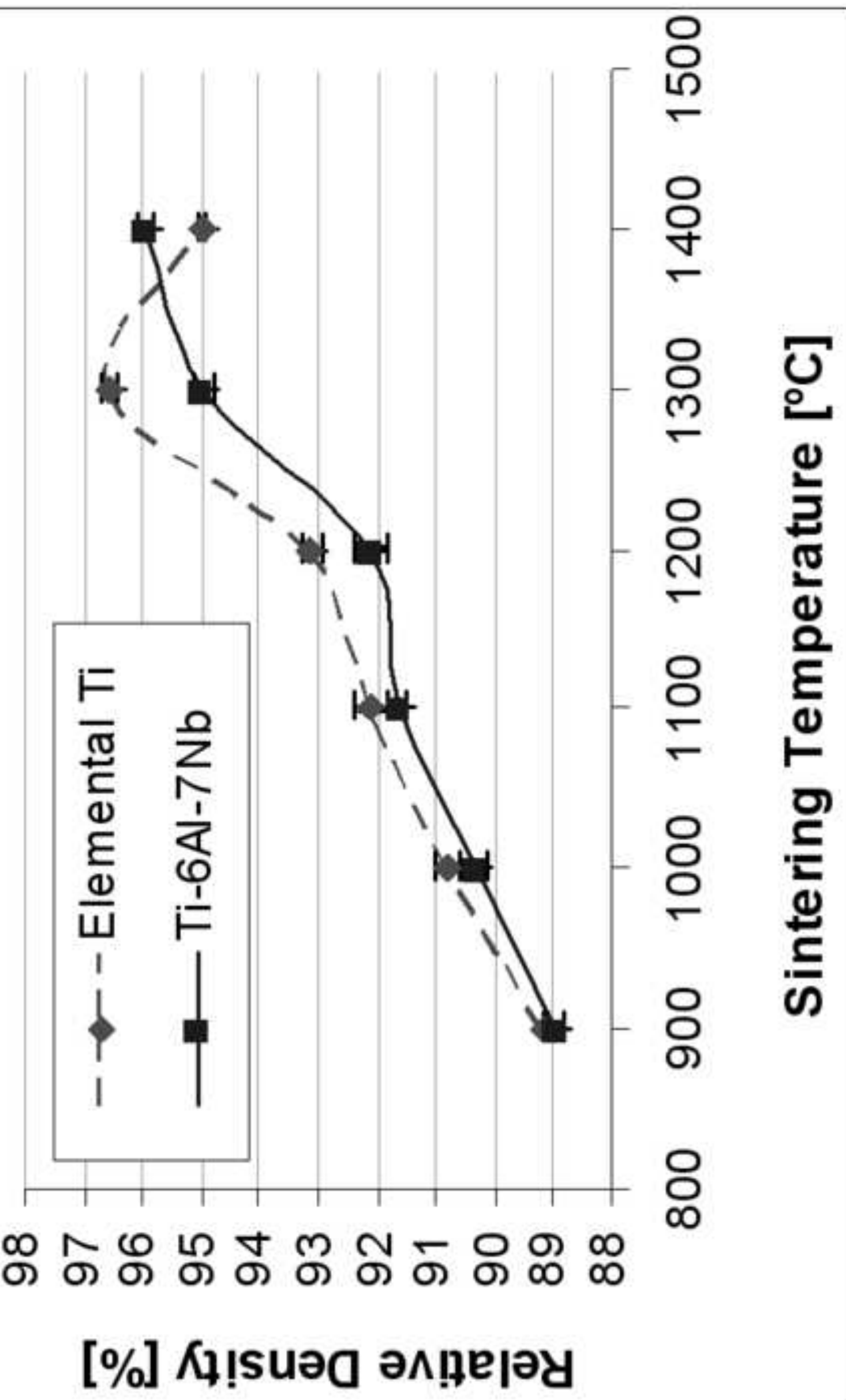



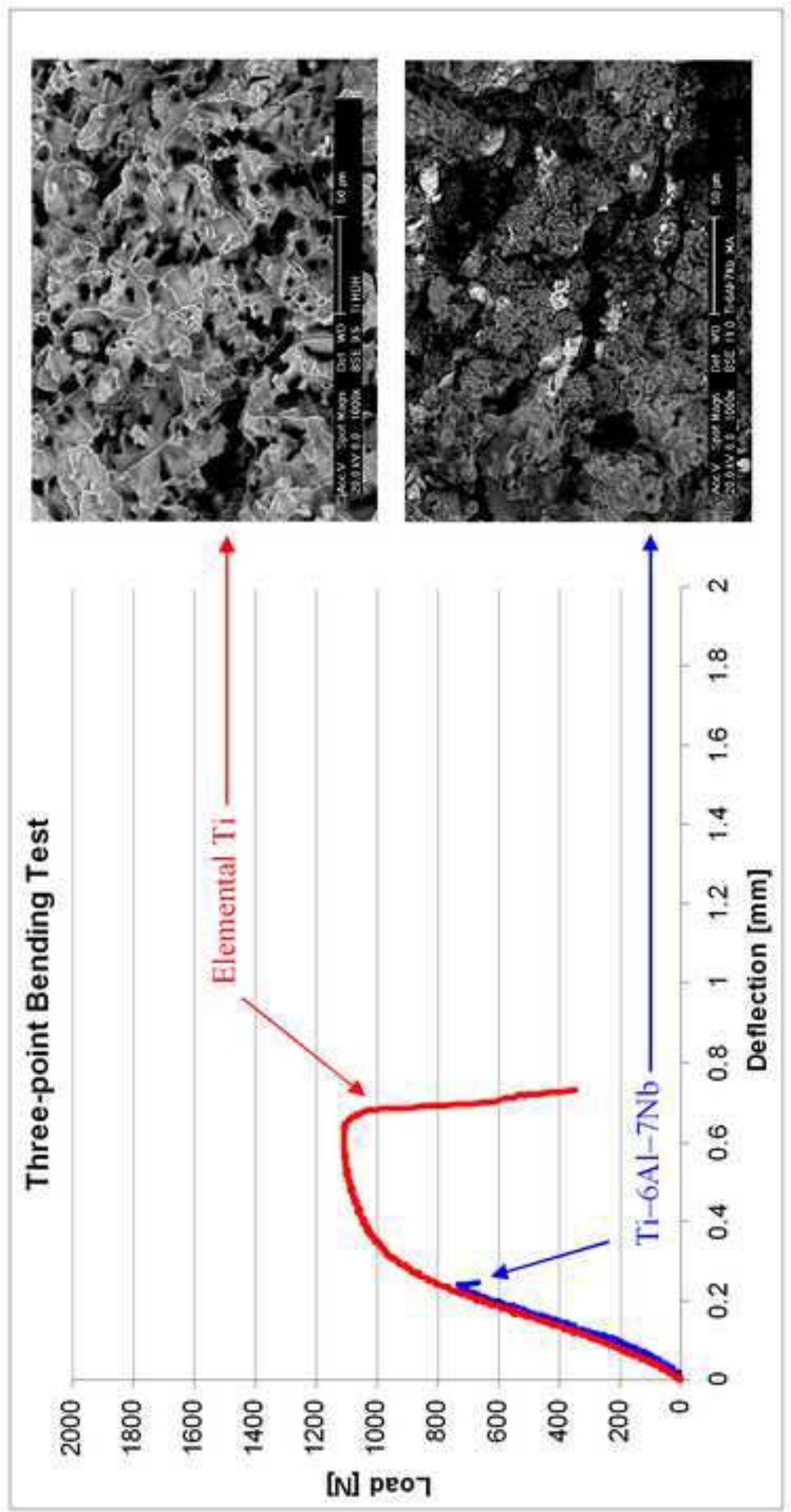

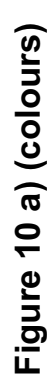



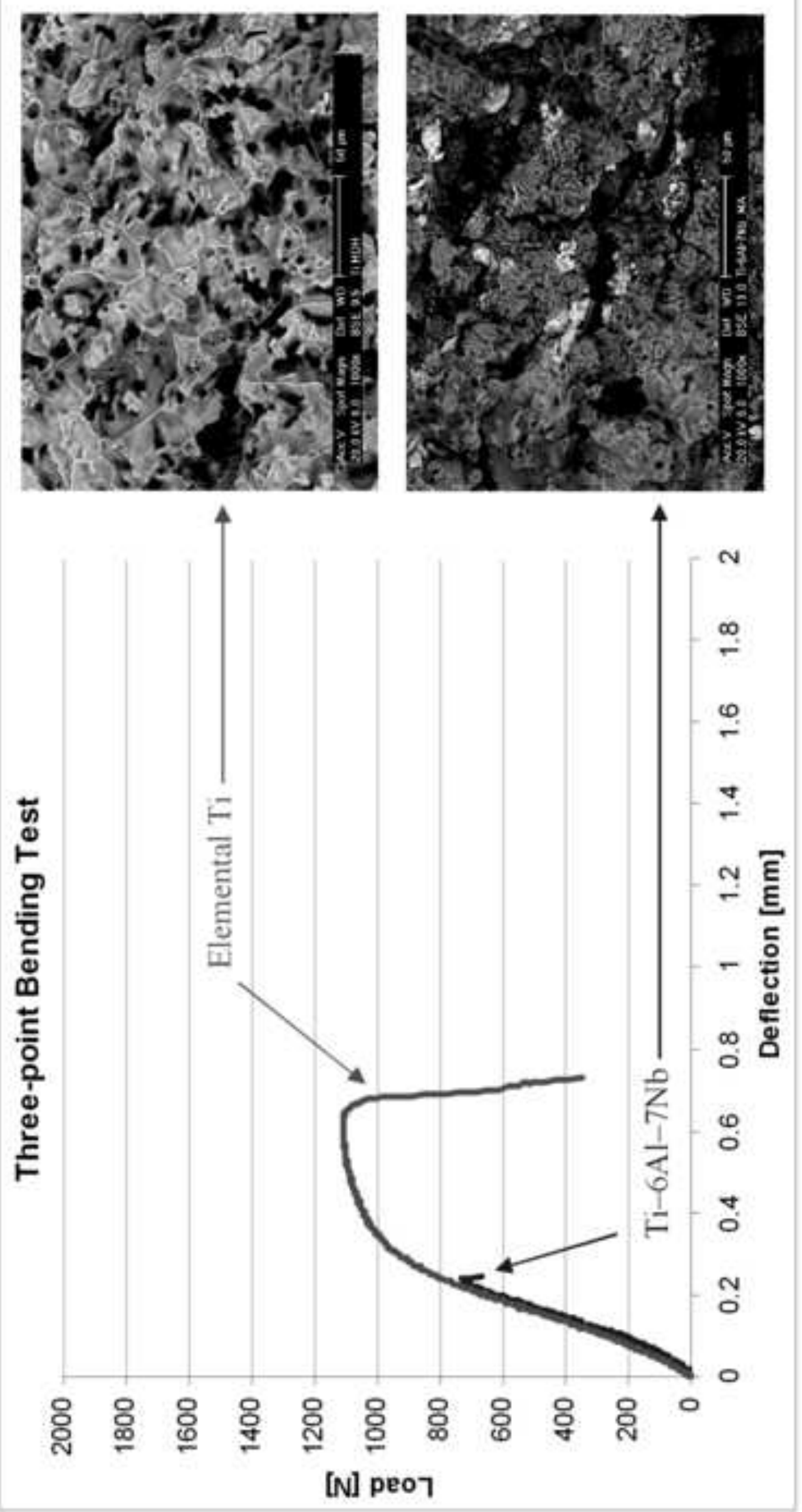

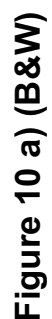




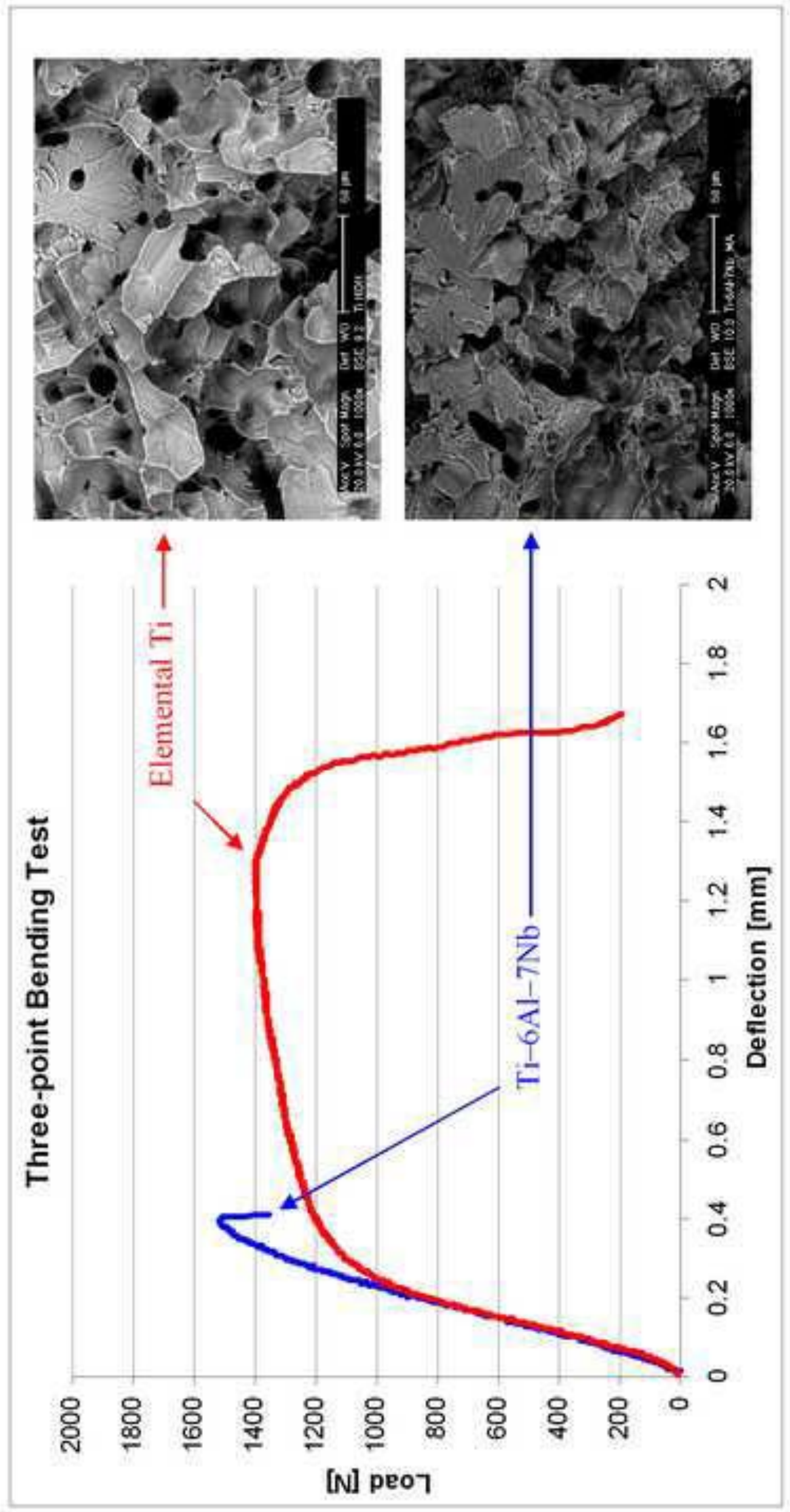




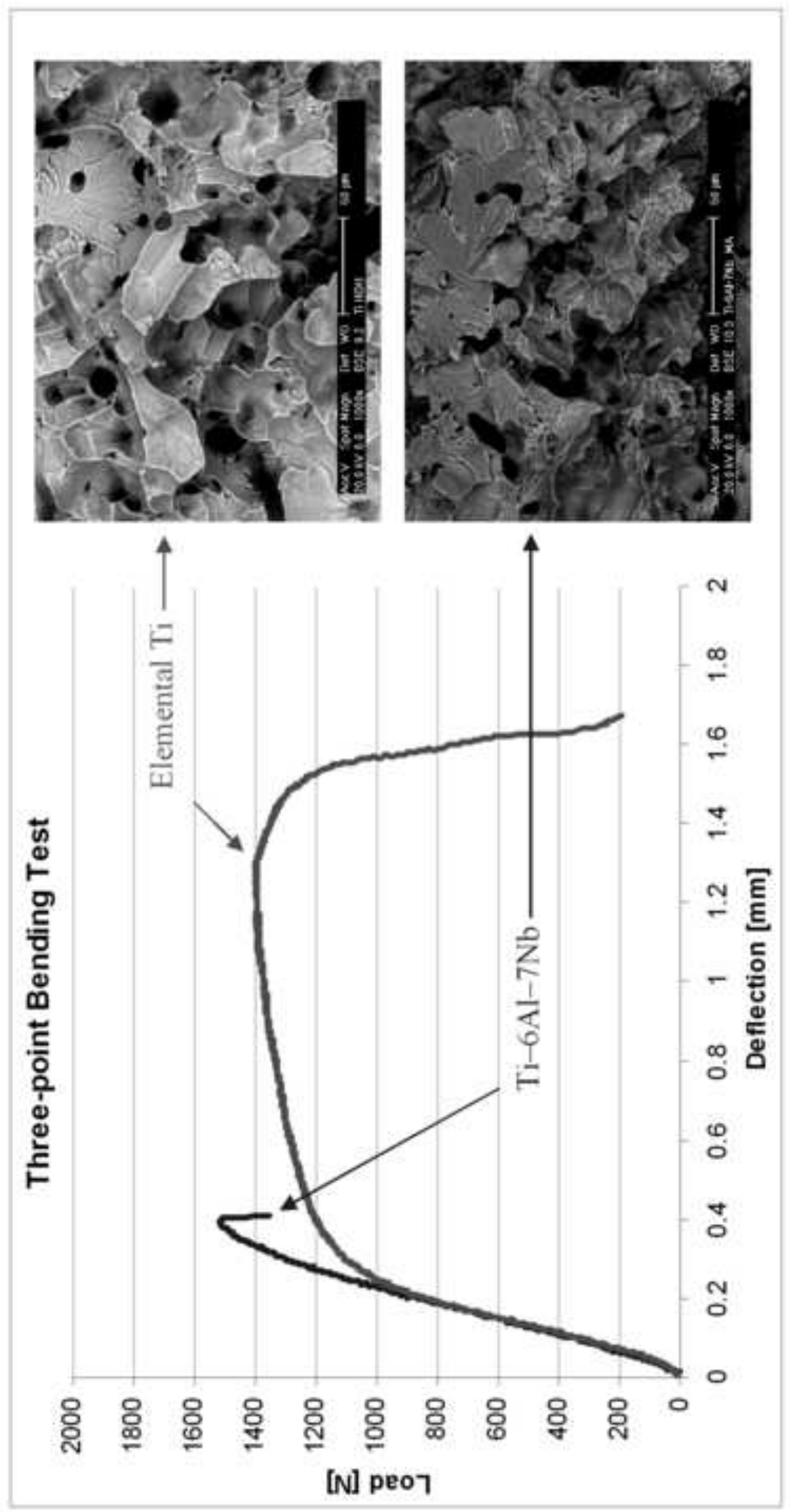



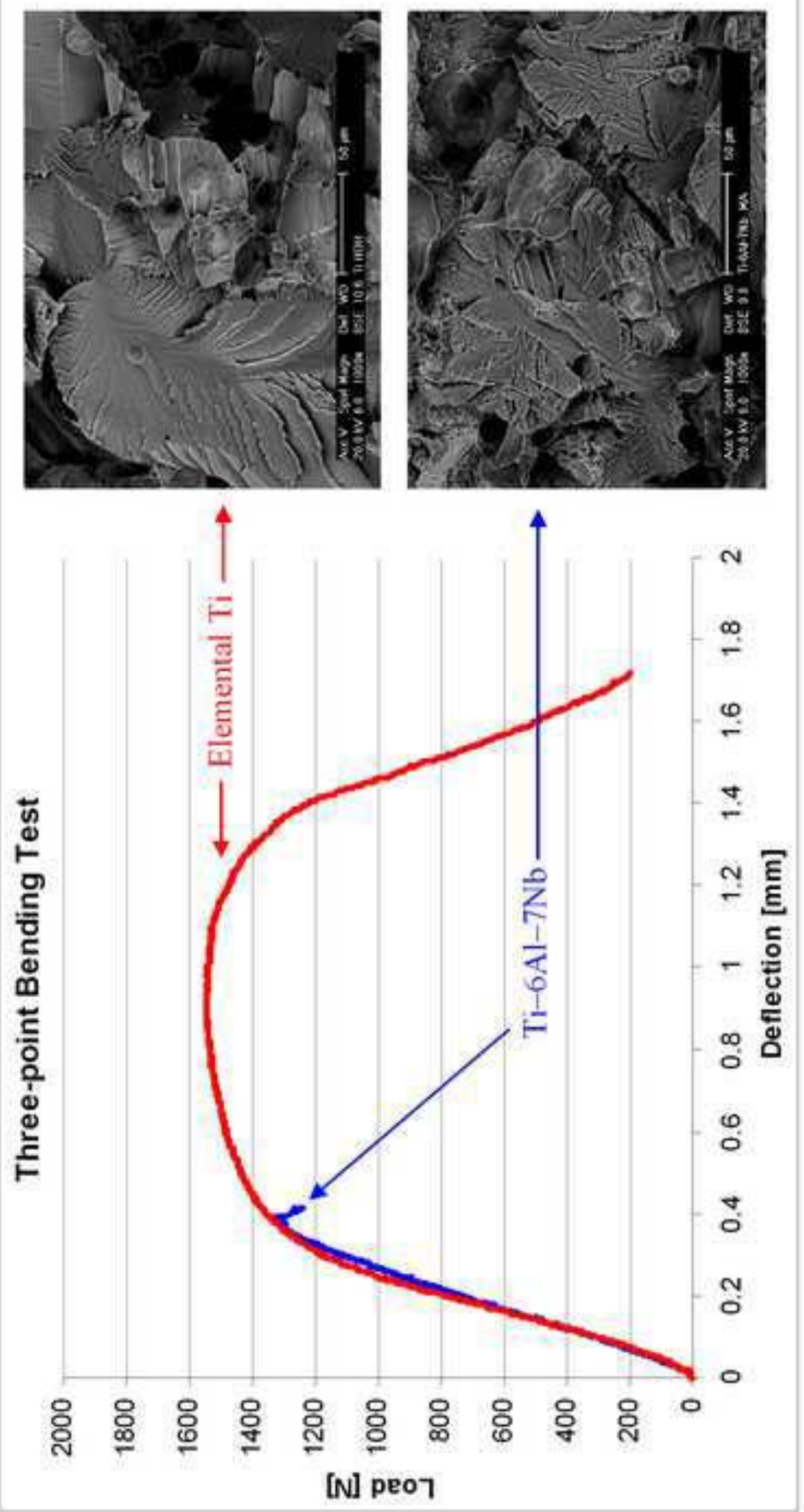

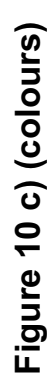




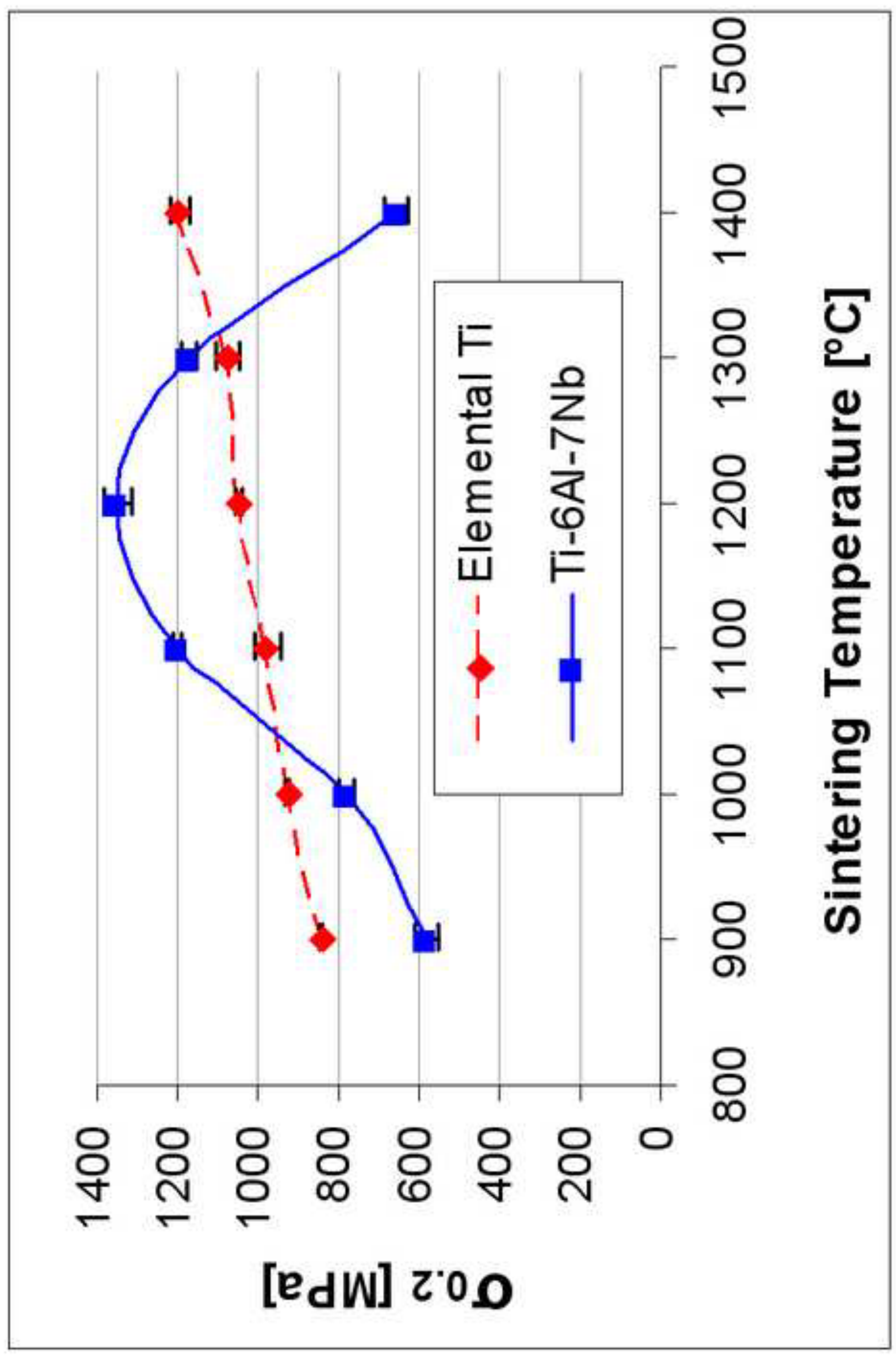




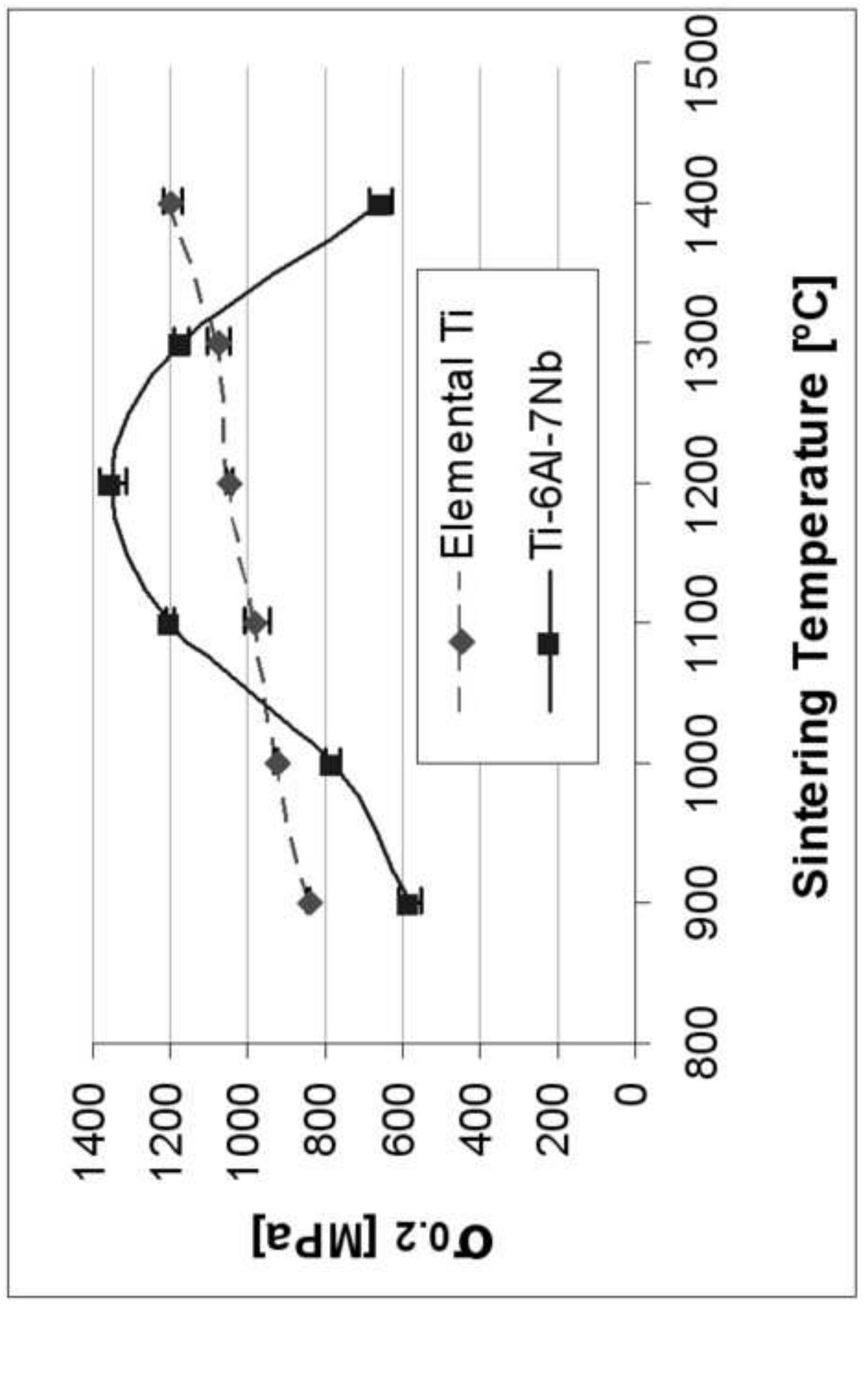




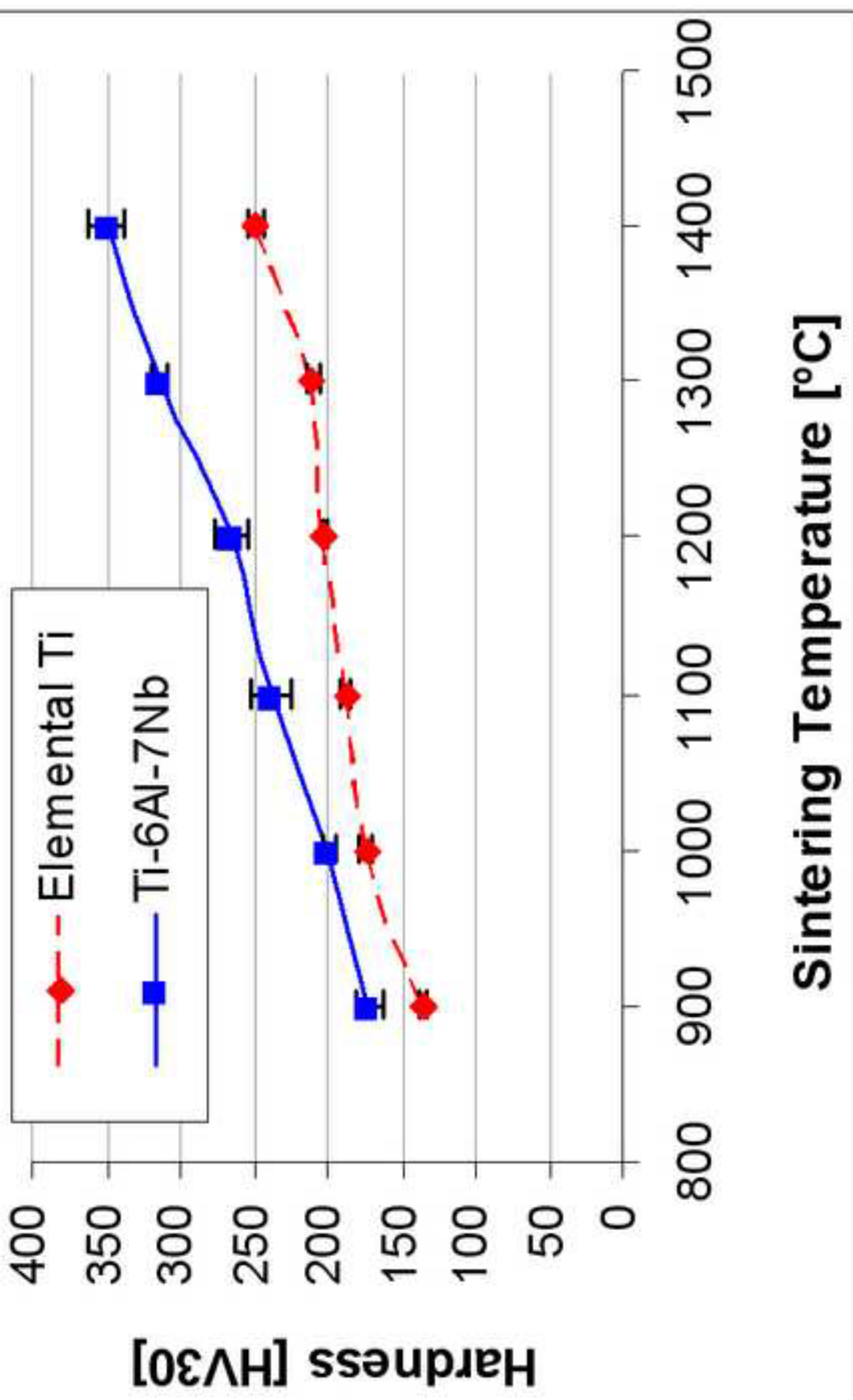




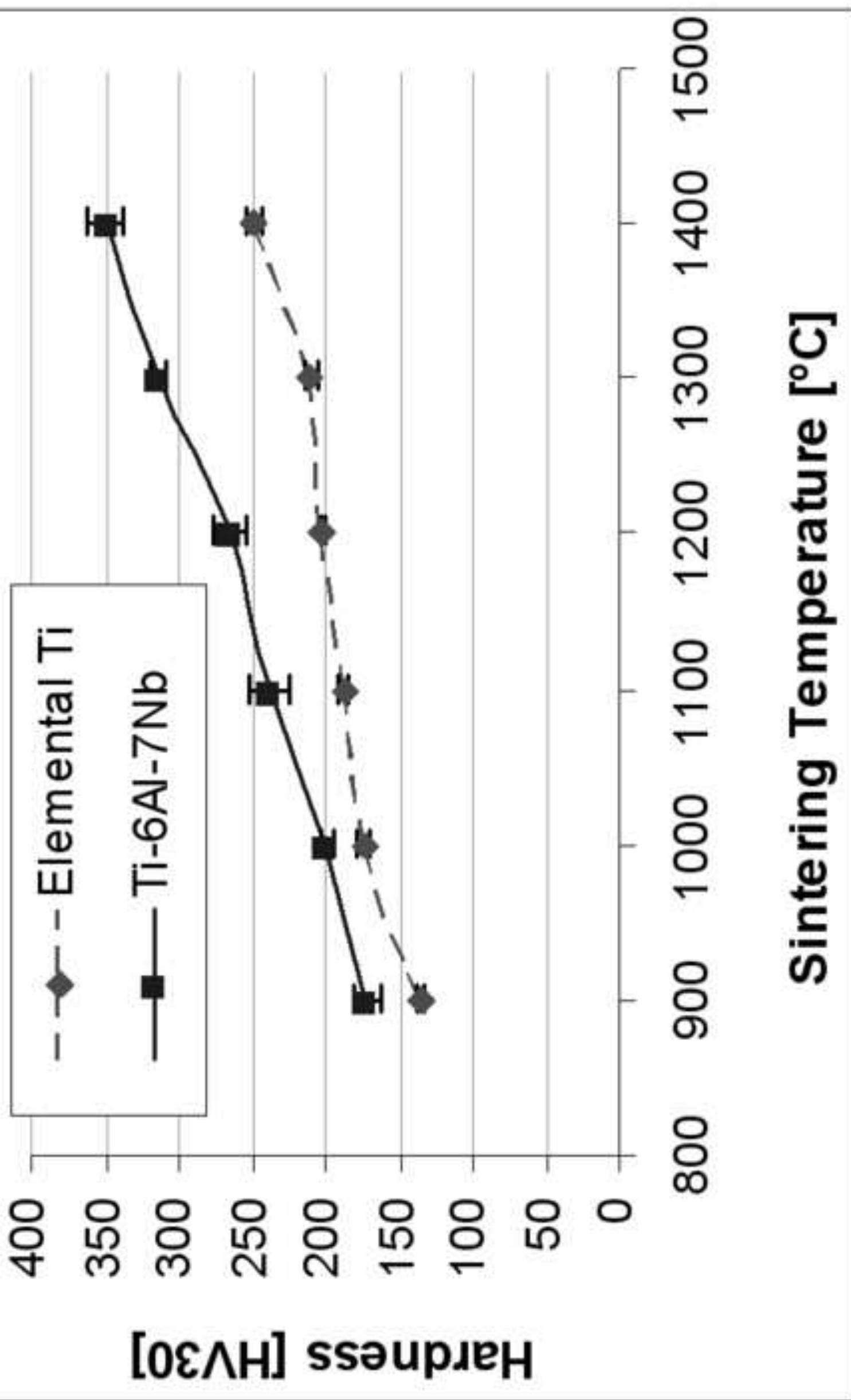



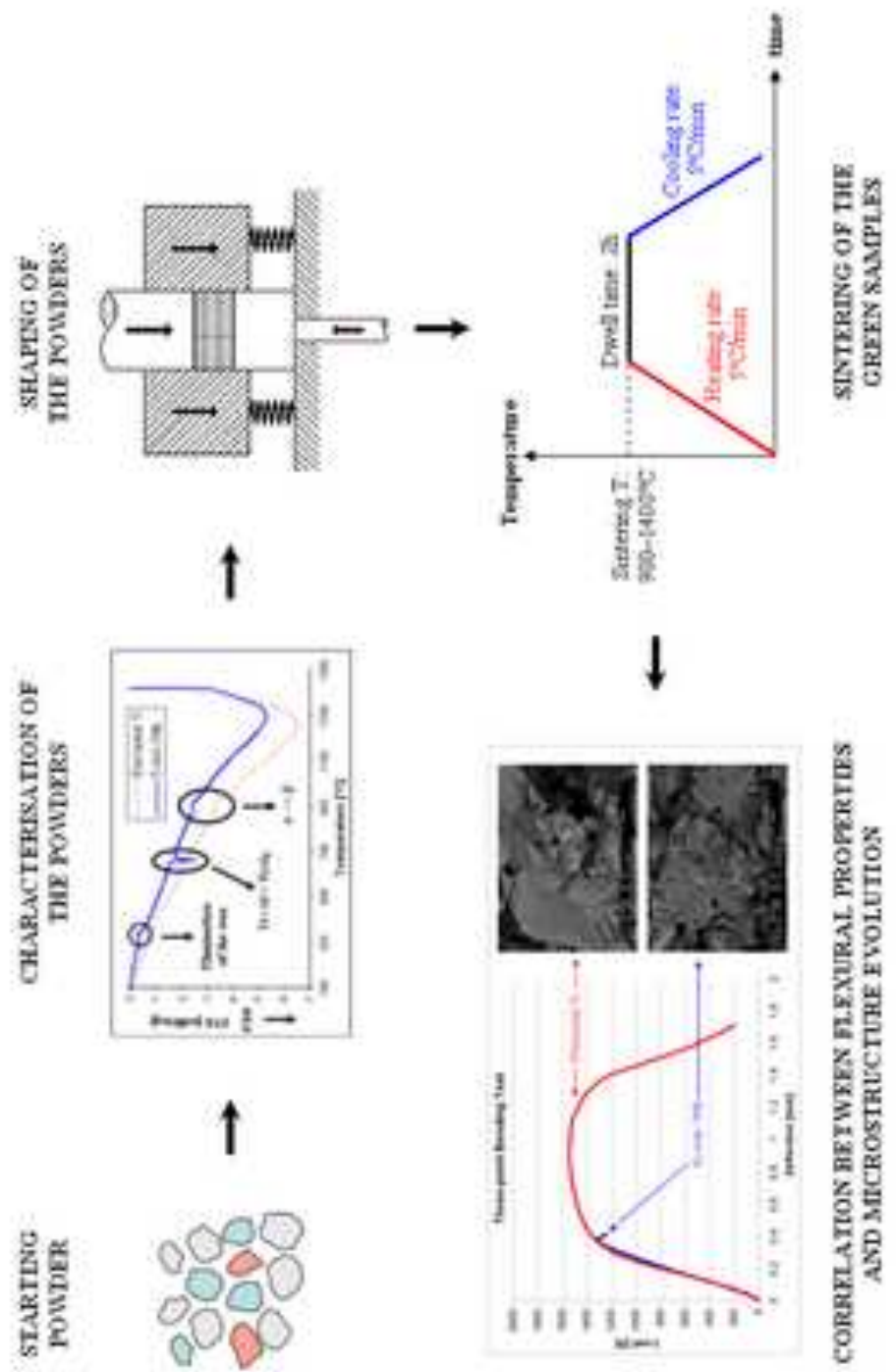